NASA/TM—2007-214901

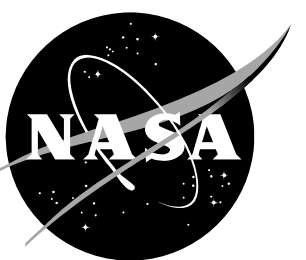

\title{
Vertical Drop Testing and Analysis of the Wasp Helicopter Skid Gear
}

Karen E. Jackson and Yvonne T. Fuchs

Langley Research Center, Hampton, Virginia 


\section{NASA STI Program ... in Profile}

Since its founding, NASA has been dedicated to the advancement of aeronautics and space science. The NASA scientific and technical information (STI) program plays a key part in helping NASA maintain this important role.

The NASA STI program operates under the auspices of the Agency Chief Information Officer. It collects, organizes, provides for archiving, and disseminates NASA's STI. The NASA STI program provides access to the NASA Aeronautics and Space Database and its public interface, the NASA Technical Report Server, thus providing one of the largest collections of aeronautical and space science STI in the world. Results are published in both non-NASA channels and by NASA in the NASA STI Report Series, which includes the following report types:

- TECHNICAL PUBLICATION. Reports of completed research or a major significant phase of research that present the results of NASA Programs and include extensive data or theoretical analysis. Includes compilations of significant scientific and technical data and information deemed to be of continuing reference value. NASA counterpart of peerreviewed formal professional papers but has less stringent limitations on manuscript length and extent of graphic presentations.

- TECHNICAL MEMORANDUM. Scientific and technical findings that are preliminary or of specialized interest, e.g., quick release reports, working papers, and bibliographies that contain minimal annotation. Does not contain extensive analysis.

- CONTRACTOR REPORT. Scientific and technical findings by NASA-sponsored contractors and grantees.
- CONFERENCE PUBLICATION. Collected papers from scientific and technical conferences, symposia, seminars, or other meetings sponsored or co-sponsored by NASA.

- SPECIAL PUBLICATION. Scientific, technical, or historical information from NASA programs, projects, and missions, often concerned with subjects having substantial public interest.

- TECHNICAL TRANSLATION. Englishlanguage translations of foreign scientific and technical material pertinent to NASA's mission.

Specialized services also include creating custom thesauri, building customized databases, and organizing and publishing research results.

For more information about the NASA STI program, see the following:

- Access the NASA STI program home page at http://www.sti.nasa.gov

- E-mail your question via the Internet to help@sti.nasa.gov

- Fax your question to the NASA STI Help Desk at (301) 621-0134

- Phone the NASA STI Help Desk at (301) 621-0390

- Write to:

NASA STI Help Desk

NASA Center for AeroSpace Information 7115 Standard Drive Hanover, MD 21076-1320 
NASA/TM-2007-214901

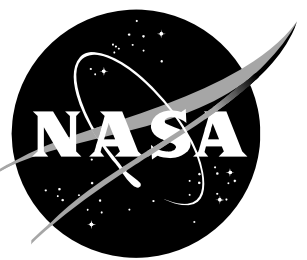

\section{Vertical Drop Testing and Analysis of the Wasp Helicopter Skid Gear}

Karen E. Jackson and Yvonne T. Fuchs

Langley Research Center, Hampton, Virginia

National Aeronautics and

Space Administration

Langley Research Center

Hampton, VA 23681

September 2007 
Available from:

NASA Center for AeroSpace Information 7115 Standard Drive

Hanover, MD 21076-1320

(301) 621-0390

This report is also available in electronic form at http://ntrs.nasa.gov 


\title{
Vertical Drop Testing and Analysis of the Wasp Helicopter Skid Gear
}

\author{
Karen E. Jackson and Yvonne T. Fuchs \\ NASA Langley Research Center \\ Hampton, VA 23681-2199
}

\section{ABSTRACT}

This report describes an experimental program to assess the impact performance of a skid gear for use on the Wasp kit-built helicopter, which is marketed by HeloWerks, Inc. of Hampton, Virginia. In total, five vertical drop tests were performed. The test article consisted of a skid gear mounted beneath a steel plate. A seating platform was attached to the upper surface of the steel plate, and two $95^{\text {th }}$ percentile Hybrid III male Anthropomorphic Test Devices (ATDs) were seated on the platform and secured using a four-point restraint system. The test article also included ballast weights to ensure the correct position of the Center-of-Gravity (CG). Twentysix channels of acceleration data were collected per test at 50,000 samples per second. The five drop tests were conducted on two different gear configurations. The details of these test programs are presented, as well as an occupant injury assessment. Finally, a finite element model of the skid gear test article was developed for execution in LS-DYNA, an explicit nonlinear transient dynamic code, for predicting the skid gear and occupant dynamic responses due to impact.

\section{INTRODUCTION}

HeloWerks, Inc. of Hampton, VA markets the HX-2 Wasp, a 1,000-lb. gross weight kit-built two-seat helicopter fabricated using monocoque composite sandwich construction. The helicopter is 19-ft. long, 9-ft. high, and 7-ft. wide at the skids. A photo of the helicopter is shown in Figure 1. During a flight demonstration of the prototype aircraft, the pilot accidentally shut off the engine during hovering flight resulting in an injurious crash. The flight demonstration aircraft was outfitted with a composite skid gear that was designed for energy absorption; however, during the actual crash, the skid gear snapped and failed, absorbing very little crash energy. This accident led HeloWerks to redesign the skid gear of the Wasp helicopter and to approach NASA to conduct a test evaluation program.

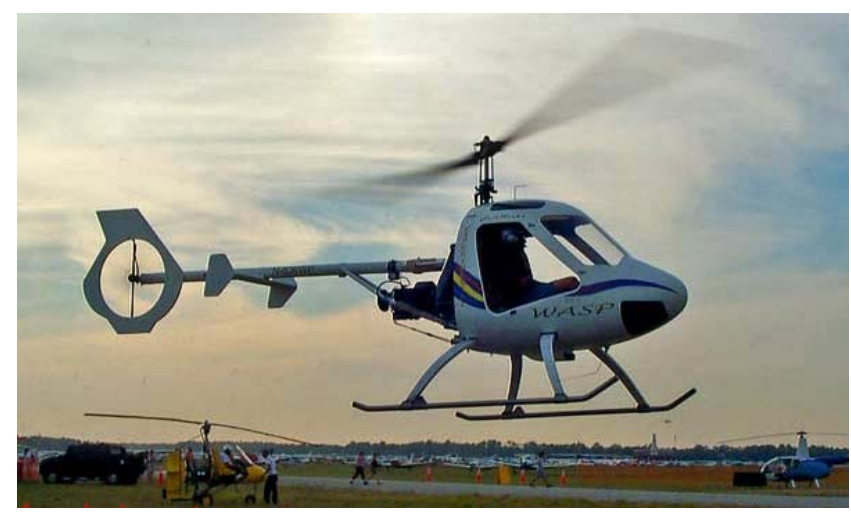

Figure 1. Photograph of the Wasp helicopter. 
A cooperative research program was developed between HeloWerks, Inc. and NASA Langley Research Center to evaluate the redesigned skid gear. This research program was sponsored under a Space Act Agreement (SAA) [1] that was signed on October 24, 2006. The SAA defines a joint research program in which HeloWerks provided the test articles and NASA instrumented the test articles, performed the vertical drop tests, and shared all test data, pre- and post-test photos, and film/video coverage with HeloWerks. The benefit of the program to HeloWerks was a new skid gear with demonstrated crash energy absorption that met the Federal Aviation Regulation (FAR Part 27) requirements for FAA certification [2]. The benefit to NASA was the acquisition of anthropomorphic test device (ATD) vertical response test data, obtained from a fairly simple test article, for use in validating LS-DYNA occupant analysis models. The SAA allows NASA to share this data publically with the aerospace industry as documented in this paper.

In total, five vertical drop tests were performed on two different skid gear configurations. Two vertical drop tests at 5- and 8 -ft/s were conducted on the initial redesign of the skid gear. Following these drop tests, HeloWerks engineers made some modifications to the gear resulting in the final design configuration. Three tests were conducted on the final skid gear design at impact velocities of 8.35-, 10-, and 12.69-ft/s. This document will describe the experimental program, an injury assessment performed on occupant responses measured during drop testing of the final skid gear design, and a summary of the occupant modeling approach and results.

\section{EXPERIMENTAL PROGRAM}

\section{A. Initial Skid Gear Redesign}

\section{Test Description}

Two vertical drop tests were performed on November 21, 2006, of the initial skid gear redesign. The first test was performed at $5.0-\mathrm{ft} / \mathrm{s}$ and the second test was performed at $8.0-\mathrm{ft} / \mathrm{s}$, using the same test article. A photo of the test article during construction is shown in Figure 2(a). This photo shows the steel plate and the plywood seating platform, along with two foam seat cushions. The slots cut in the top back of the seating platform are for seatbelt restraint systems used to secure the dummy occupants. A pre-test photo of the complete test article is shown in Figure 2(b). The fully instrumented test article weighed 1,064 lb, including $320 \mathrm{lbs}$ of ballast and $450 \mathrm{lbs}$ for the two $95^{\text {th }}$ percentile Hybrid III male ATDs. A schematic of the skid gear is shown in Figure 3, in which the parts of the skid gear are labeled including the crossbeams, struts, saddles, sleeves, and skid beams.

As mentioned previously, the original skid gear used on the Wasp helicopter was a composite design that did not function properly in an actual crash. The skid gear depicted in Figure 2(b) was an initial redesign, based on the work reported in Reference 3. The redesigned gear was fabricated using aluminum circular cross-section tubes. The tubes were reinforced at the crossbeam attachments using metal sleeves and at the intersection with the skid beams using saddles to prevent premature collapse and local buckling of the gear. These parts are shown in Figure 3.

An opening was cut into the seat platform to allow space for seat foam filler, as shown in Figure 3. The foam filler space on the left side of the platform was filled with several layers of Styrofoam, as shown in Figure 4(a). On the right side, three blocks of polyisocyanurate foam 
were used, as shown in Figure 4(b), with two blocks facing forward and one intersecting block positioned laterally. Note that the dummy occupant designated ATD-1 is seated on the Styrofoam layers on the left side of the seating platform and ATD-2 is seated on the polyisocyanurate foam blocks on the right side of the seating platform.

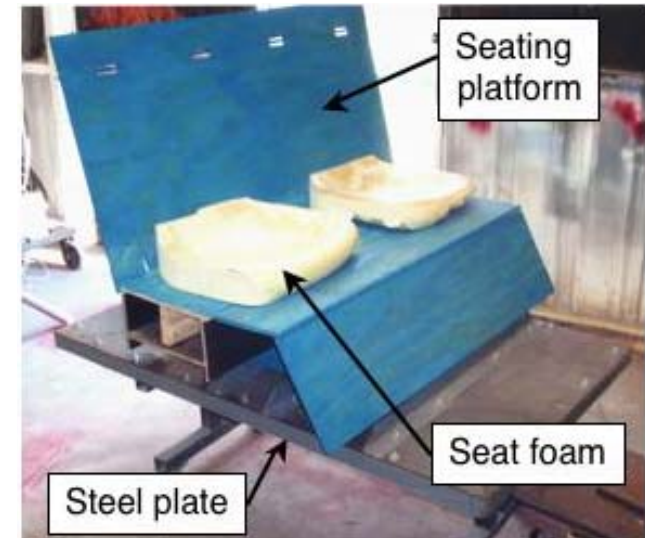

(a) Preliminary photo of test article.

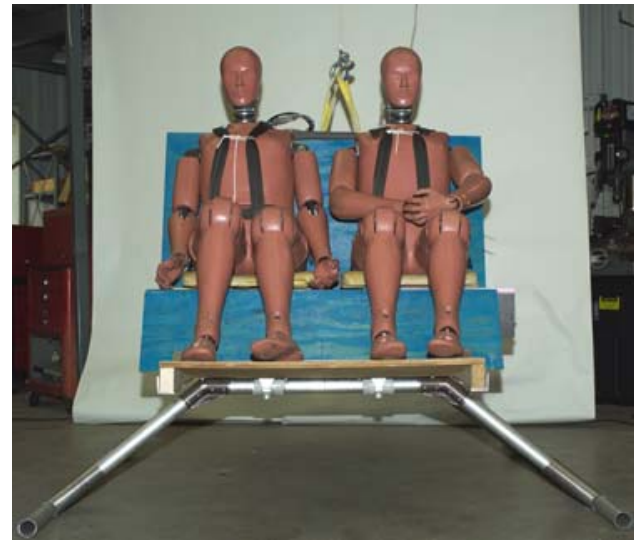

(b) Photo of final test article.

Figure 2. Photographs of the test article.

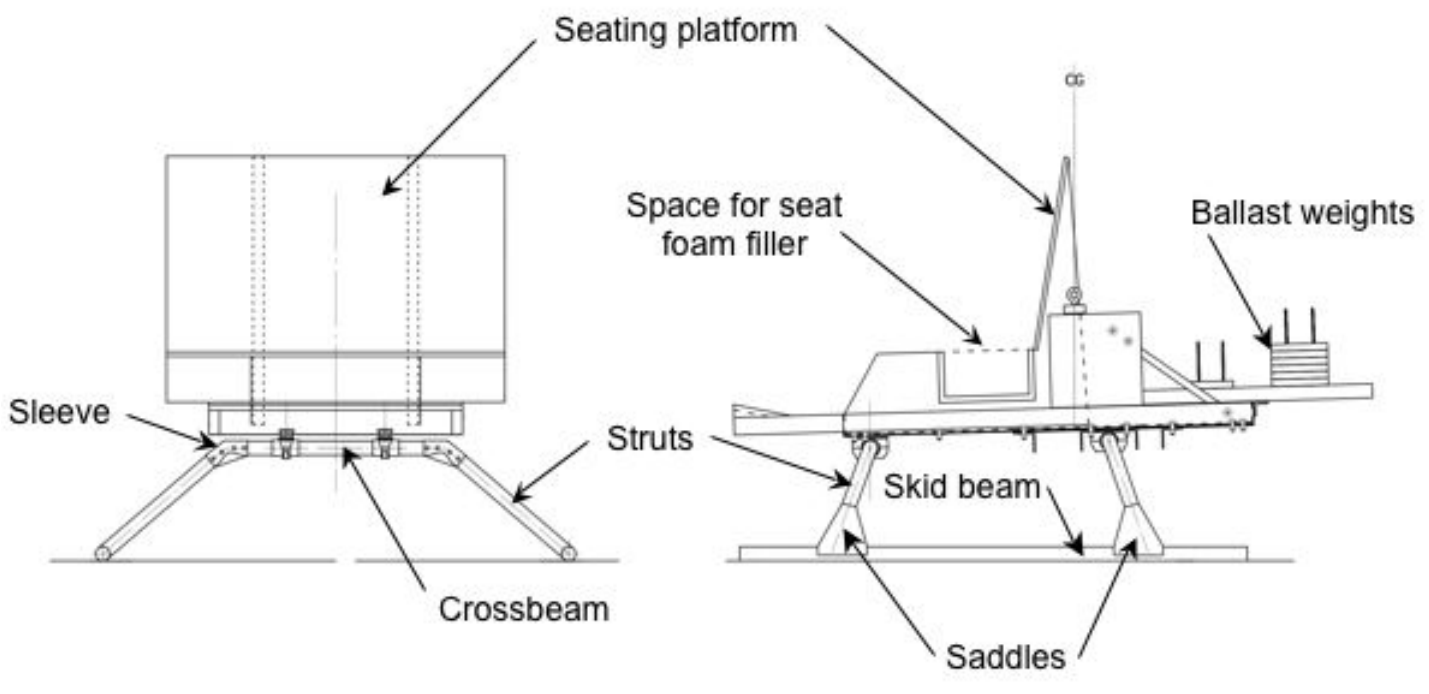

(a) Front view.

(b) Side view.

Figure 3. Schematic of test article.

The test article and ATDs were instrumented with a total of 26 accelerometers and 2 lumbar load cells for the 5- and 8-ft/s vertical drop tests of the initial skid gear redesign. The accelerometer locations on the steel plate, the seating platform, and the ATDs are shown in Figures 5(a) through 5(c), respectively. Five 200-g accelerometers were mounted to the steel plate to record vertical accelerations at the center and four corners of the plate near the skid gear attachment points, as shown in Figure 5(a). Two tri-axial accelerometers were mounted to the left and right sides of the seating platform to record longitudinal, lateral, and vertical accelerations. A single vertical accelerometer was located in the middle of the platform, as shown in Figure 5(b). The ATDs were instrumented with seven accelerometers (tri-axial accelerometers in the pelvis and chest and one vertical accelerometer in the head). The ATDs were also instrumented with lumbar load cells. All accelerometers were calibrated to $0 \mathrm{~g}$ prior to each test. Test data were collected at 50,000 samples per second using a digital data acquisition system. 


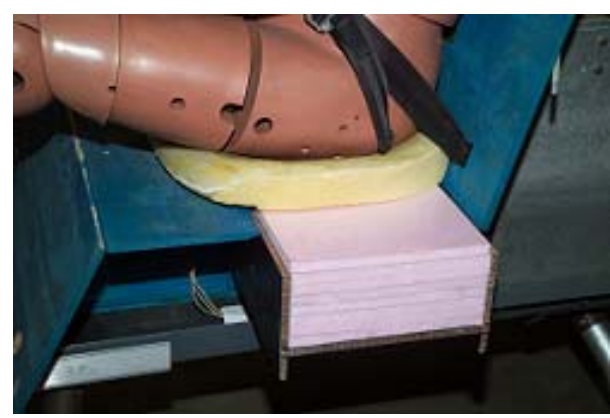

(a) Styrofoam layers.

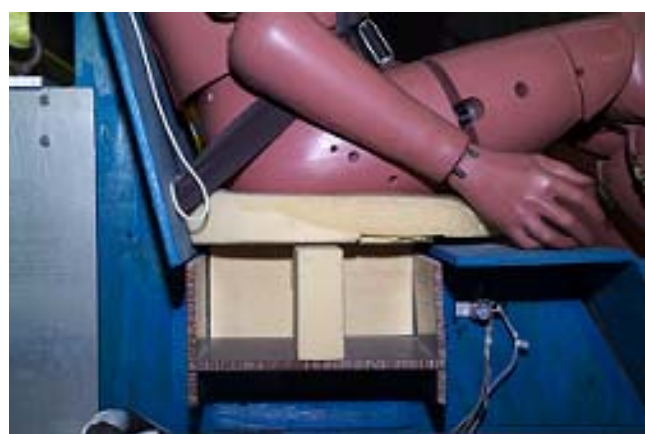

(b) Polyisocyanurate blocks.

Figure 4. Styrofoam and polyisocyanurate foam fillers.

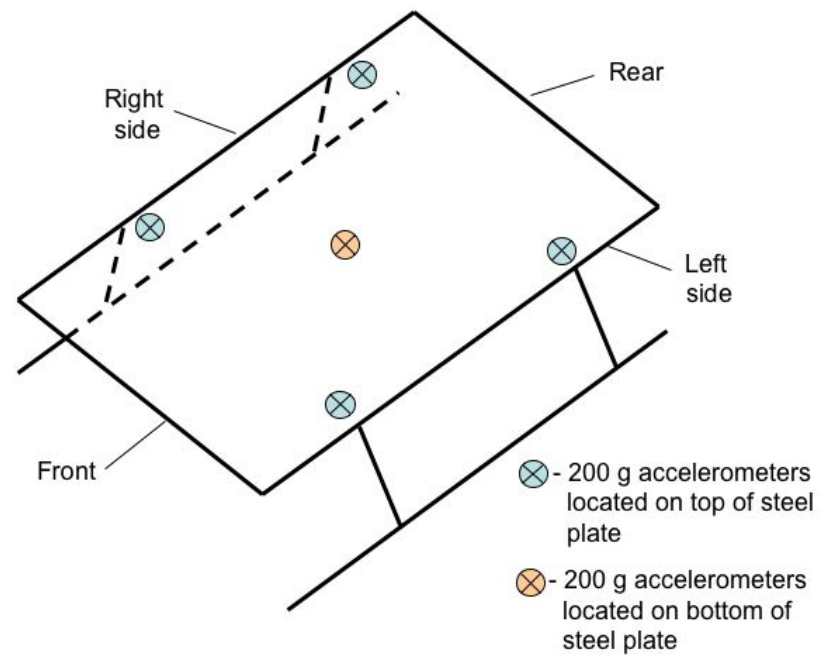

(a) Steel plate.

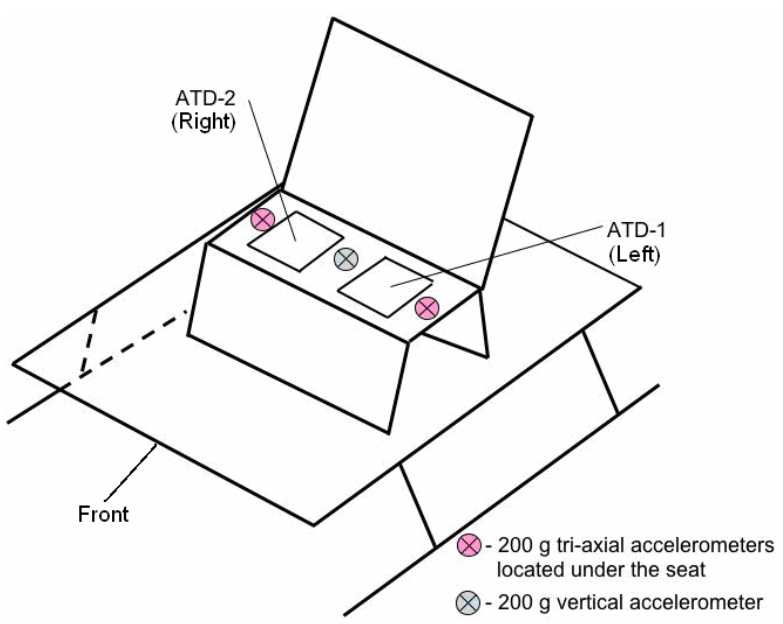

(b) Seating platform.

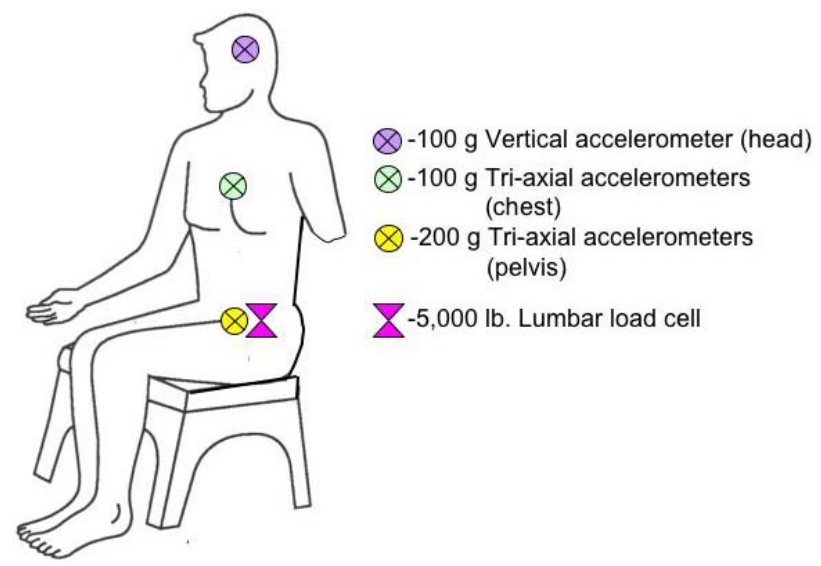

(c) ATD (typical).

Figure 5. Instrumentation layout.

The vertical drop tests were performed by attaching lifting cables to the test article, raising the test article through its center-of-gravity (CG) to the correct drop height, and then releasing the test article to impact a smooth concrete surface. 


\section{Test Results: 5-ft/s Vertical Drop Test}

Following the 5-ft/s vertical drop test, which was conducted by releasing the test article from a height of 4.7-in., it was determined that the lumbar load cells did not function properly. Consequently, no lumbar load data were collected for comparison with injury criteria. However, all acceleration data were collected successfully. In general, the lateral and longitudinal channels collected for the ATD dummy occupants were extremely low in comparison to the vertical channels. Consequently, these channels are not presented in the paper. Post-test measurements of permanent deformation show that the skid gear had only 0.3 -inches of measured spread. Also, no crushing of either seat foam filler was observed post-test.

Acceleration responses of the steel plate and seating platform are shown in Figures 6(a) and 6(b), respectively. These and all acceleration time history curves shown in the paper (except where noted) were filtered using an SAE Channel Filter Class (CFC) 20 filter [4], which is a low pass filter with a cut off frequency of $33.5 \mathrm{~Hz}$. Also, note that Figure 6(a) is labeled to orient the reader. The labels indicate pre-release of the test article, release, free fall during which the test article experiences approximately $-1-\mathrm{g}$ acceleration due to gravity, and impact with a smooth concrete surface.

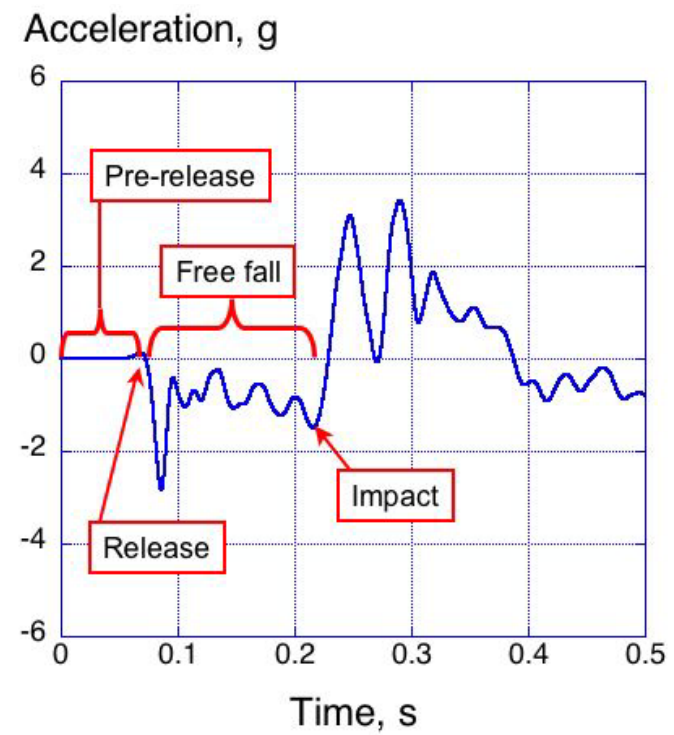

(a) Bottom of the steel plate.

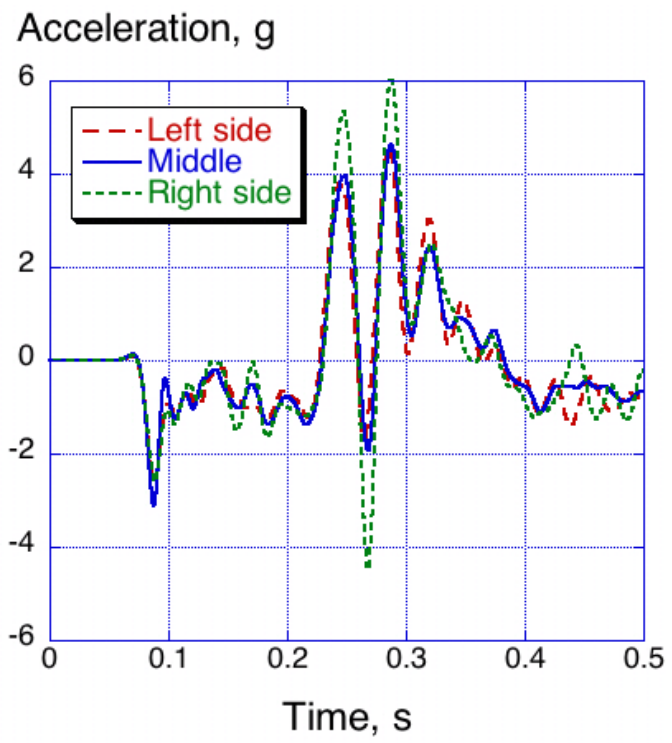

(b) Seating platform.

Figure 6. Vertical acceleration responses of the steel plate and seating platform.

For this very mild impact condition, the peak acceleration of the steel plate was $3.4 \mathrm{~g}$. The acceleration response exhibited two peaks, with the second peak having a slightly higher magnitude. The vertical acceleration responses of the left side, middle, and right side of the seat platform are shown in Figure 6(b). The three curves are nearly identical, except that the right side acceleration response has a higher magnitude than the other two curves, with a peak of $6-\mathrm{g}$. The shapes of the seating platform acceleration responses are similar to the steel plate response in that they exhibit two distinct peaks. However, the acceleration response of the steel plate is lower in magnitude as compared with the seating platform.

Comparisons of the vertical acceleration responses of the head, chest, and pelvis of the right and left ATD dummy occupants are shown in Figure 7(a) through 7(c), respectively, for the 5-ft/s 
drop test conducted on the initial skid gear redesign. As a reminder, these acceleration responses have been filtered using an SAE CFC20 filter. The magnitudes of the acceleration responses shown in Figure 7 range from 4- to 6-g. The acceleration responses of the head have the lowest magnitude (4 g's) and the pelvic acceleration responses have the highest magnitude (6 g's). Also, only slight differences are seen between the ATD-1 and ATD-2 head and chest acceleration responses. However, the pelvic acceleration response of ATD-2 is higher in magnitude than the ATD-1 response. Based on the data presented in Figure 6(b), the acceleration response of the right side of the seating platform is higher than the corresponding accelerations from the left side and middle positions. This variation is reflected in the ATD pelvic acceleration responses and may be due to a slight roll angle attitude of the test article at impact.

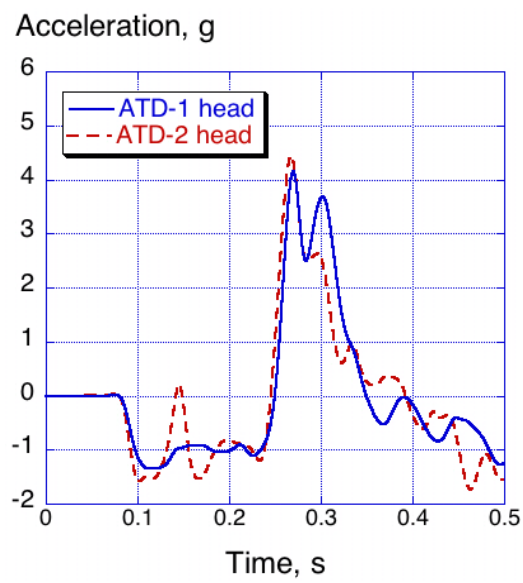

(a) Head.

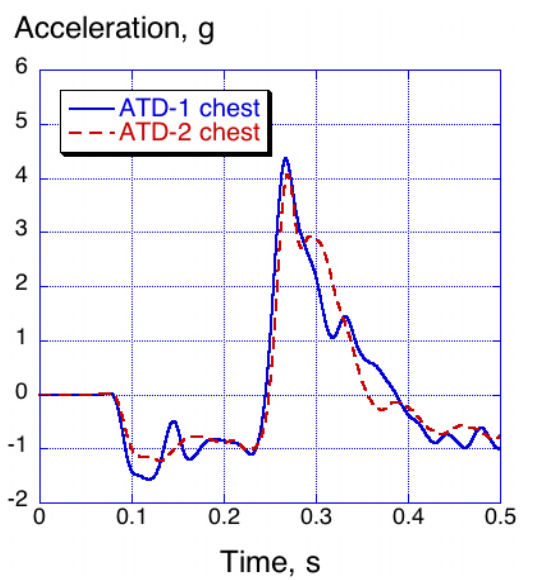

(b) Chest.

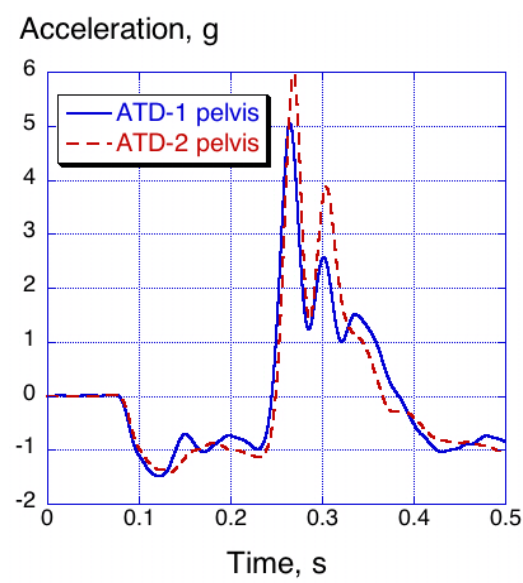

(c) Pelvis.

Figure 7. Plots of ATD acceleration responses of the head, chest, and pelvis for the $5-\mathrm{ft} / \mathrm{s}$ drop test.

\section{Test Results: 8-ft/s Vertical Drop Test}

Following the 5-ft/s vertical drop test, the test article was inspected for damage and measurements of skid gear spread were made. Based on these assessments, the test article was deemed in satisfactory condition to proceed with the $8-\mathrm{ft} / \mathrm{s}$ vertical drop test. This test was conducted by releasing the test article from a height of 12-in. to impact the concrete floor. Preand post-test photographs of the test article are shown in Figure 8. During the $8-\mathrm{ft} / \mathrm{s}$ vertical drop test, the gear collapsed on the left side in the region where the strut attaches to the crossbeam. In this area, the metal sleeve was cracked and the strut showed signs of pulling out of the sleeve as a result of rivet failures. A close up photo of this region is shown in Figure 9. 


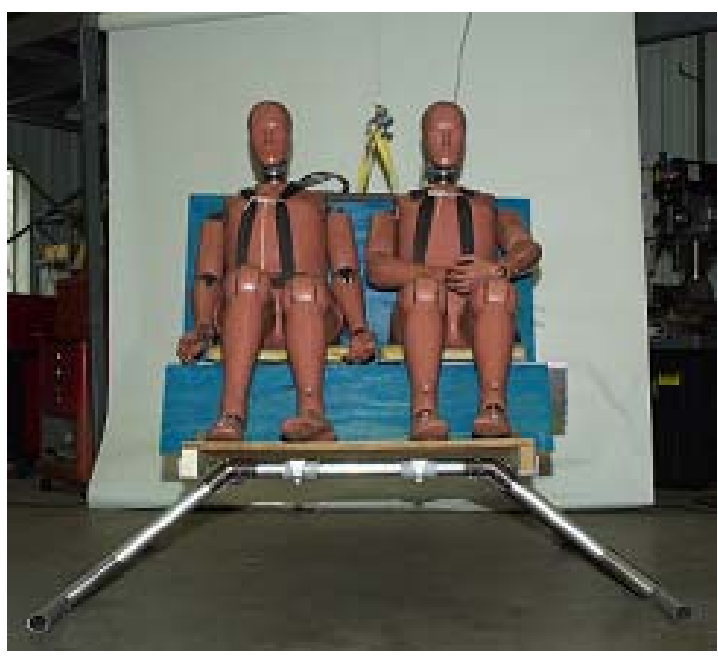

(a) Pre-test photo.

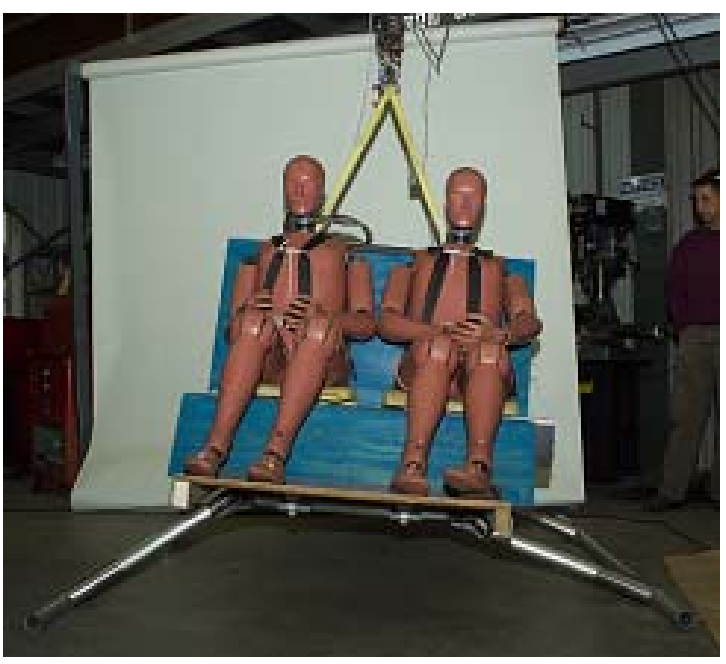

(b) Post-test photo.

Figure 8. Pre- and post-test photographs of the test article for the $8-\mathrm{ft} / \mathrm{s}$ vertical drop test.

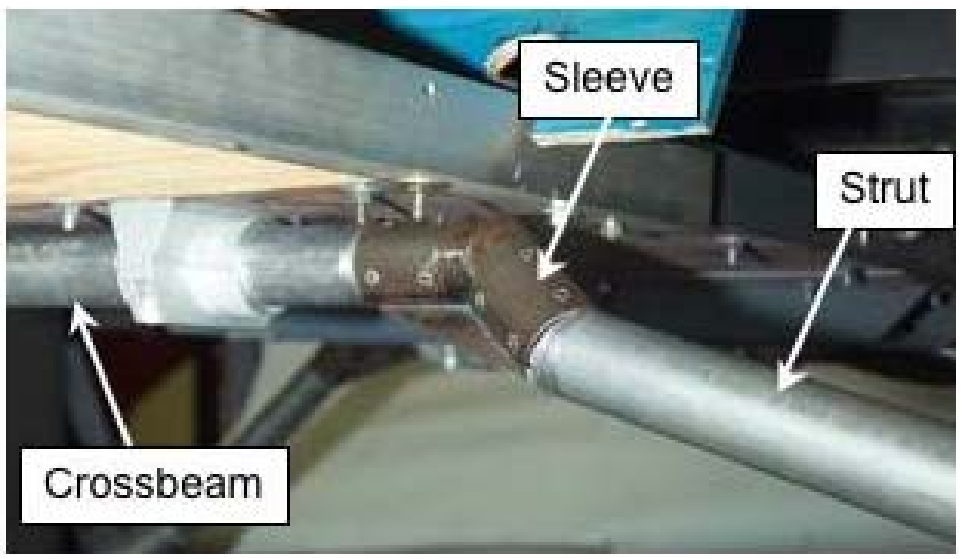

Figure 9. Close up photograph of skid gear failure region.

Acceleration responses from the steel plate and seating platform are shown in Figures 10(a) and (b) respectively, for the $8-\mathrm{ft} / \mathrm{s}$ vertical drop test. For this more severe impact condition, the peak acceleration of the steel plate was approximately $5.4 \mathrm{~g}$. The acceleration response exhibited three distinct peaks, with the first two peaks having a higher magnitude than the third. The vertical acceleration responses of the left side, middle, and right side of the seating platform are shown in Figure 10(b). The three curves are nearly identical, with each exhibiting three distinct peaks. The first peak of the left side acceleration response has the highest magnitude $(8.7-\mathrm{g}) \mathrm{of}$ the three curves. The shapes of the seat platform acceleration responses are similar to the steel plate response in that they exhibit three distinct peaks. However, the acceleration response of the steel plate is lower in magnitude in comparison with the seating platform. 


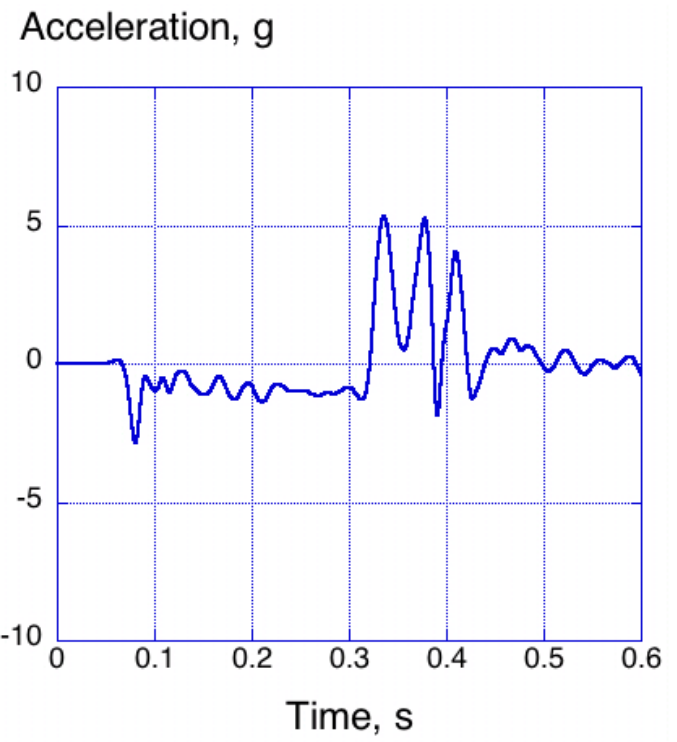

(a) Bottom center of the steel plate.

\section{Acceleration, $\mathrm{g}$}

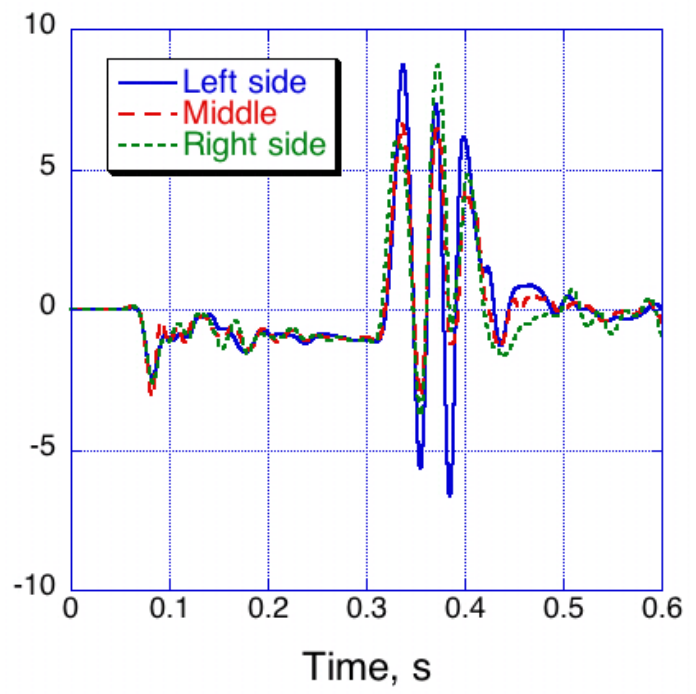

(b) Seating platform.

Figure 10. Vertical acceleration responses of the 8-ft/s drop test of the initial skid gear redesign.

Comparisons of the filtered vertical acceleration responses of the head, chest, and pelvis of the right and left ATDs are shown in Figure 11 for the 8-ft/s drop test conducted on the initial skid gear redesign. The peak magnitudes of the acceleration responses shown in Figure 11 range from 6.5- to 8.3-g. As expected, these responses are higher in magnitude than the occupant responses obtained for the 5 - $\mathrm{ft} / \mathrm{s}$ drop test. The acceleration responses of the head have the lowest magnitude $(6.5 \mathrm{~g})$ and the pelvic acceleration responses have the highest magnitude $(8.3$ g). Some differences are seen between the ATD-1 and ATD-2 acceleration responses with the ATD-2 responses having lower magnitude and a different shape than the ATD-1 responses.

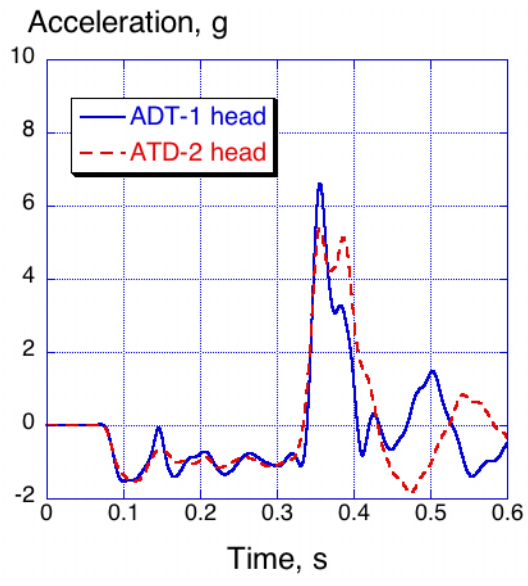

(a) Head.

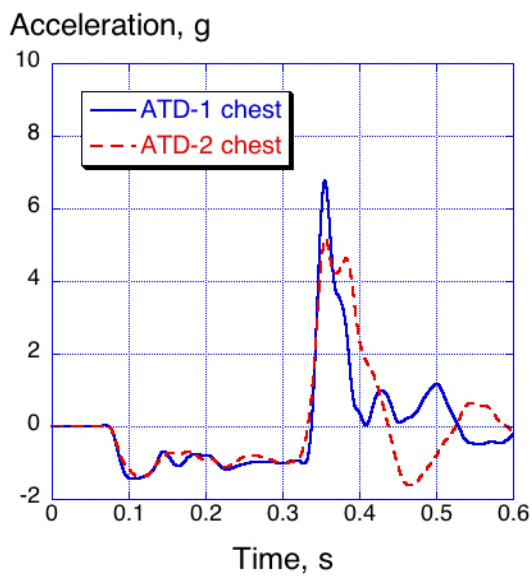

(b) Chest.

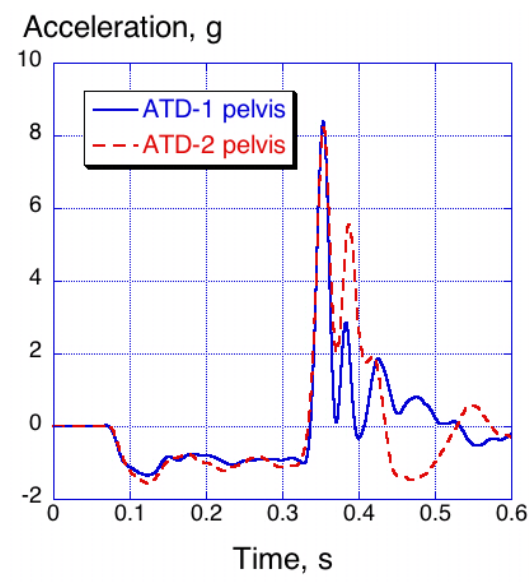

(c) Pelvis.

Figure 11. Comparisons of head, chest, and pelvis vertical acceleration responses. 


\section{B. Final Skid Gear Design}

\section{Test Description}

Following the 8-ft/s vertical drop test, it became apparent to the engineers at HeloWerks that some design changes were needed to meet the certification requirements set forth in FAR 27 for landing loads of helicopters under 7000 pounds gross weight [2]. Consequently, HeloWerks modified the gear by increasing the wall thickness and outer diameter of the struts and by shortening the struts. A series of three vertical drop tests were conducted at 8.35- 10.0- and $12.69-\mathrm{ft} / \mathrm{s}$ to qualify the final skid gear design. The test article consisted of the modified skid gear attached to a steel plate, a seating platform attached to the steel plate, ballast weights, and two $95^{\text {th }}$ percentile Hybrid III ATD dummy occupants seated side-by-side on the seating platform and restrained using a four-point seatbelt restraint system. The total weight of the test article including ballast weights and ATDs was 1,060 lbs. The test article was instrumented with 26 accelerometers using the same layout as shown in Figure 5. Test data were collected at 50,000 samples per second using a digital data acquisition system.

\section{Test Results: 8.35-ft/s Vertical Drop Test}

For this test condition, the test article was lifted to a height of 13 inches and released to impact a smooth concrete surface at $8.35-\mathrm{ft} / \mathrm{s}$. Post-test measurements of permanent deformation show that the average measured spread of the skid gear was 4.4 inches. No crushing of either the Styrofoam stack or the polyisocyanurate foam blocks was visible post-test. Pre- and post-test photographs of the test article are shown in Figure 12. Damage was observed to the metal saddles surrounding the attachment of the struts to the skid beams. This damage consisted mainly of buckling of the metal saddle, as shown in Figure 13. No cracks or rivet line failures were observed. Note that the damage shown in Figure 13 was typical of each of the metal saddles.

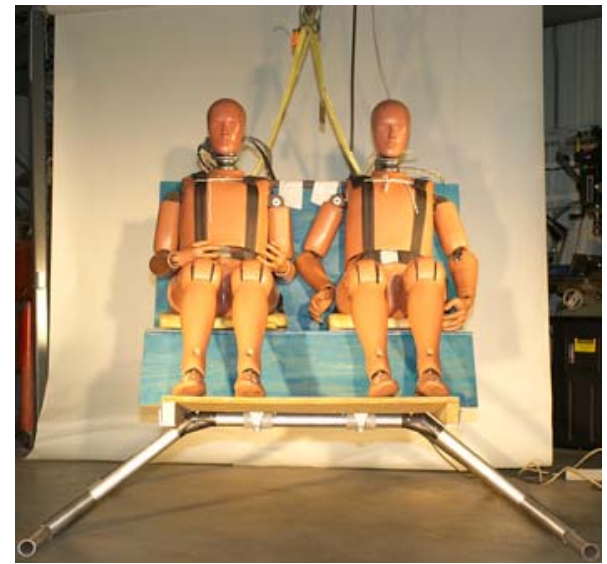

(a) Pre-test photo.

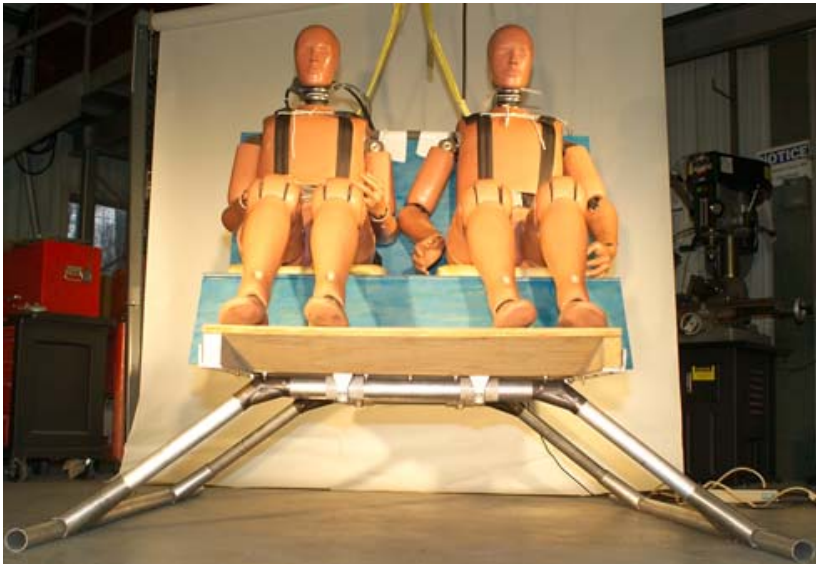

(b) Post-test photo.

Figure 12. Pre- and post-test photographs of the $8.35-\mathrm{ft} / \mathrm{s}$ vertical drop test.

Acceleration responses from the steel plate and seating platform are shown in Figures 14(a) and 14(b) respectively, for the 8.35-ft/s vertical drop test. For this impact condition, the peak acceleration of the steel plate was $4.7 \mathrm{~g}$, which is lower than the peak acceleration (5.4-g) obtained during the 8-ft/s vertical drop of the initial skid gear redesign. The acceleration response exhibited four distinct peaks of descending magnitude. The vertical acceleration responses of the left side, middle, and right side of the seat platform are shown in Figure 14(b). The three curves are nearly identical, each exhibiting three peaks ranging in magnitude from 4.7 
to $7.7 \mathrm{~g}$. These values are lower than those obtained during the 8 - $\mathrm{ft} / \mathrm{s}$ drop test of the initial skid gear redesign, shown in Figure 10. The differences in peak accelerations between the two 8-ft/s drop tests are attributed to two major sources. The first source of difference between the tests is that the initial skid gear was tested in pristine condition at $5-\mathrm{ft} / \mathrm{s}$ before being tested at $8-\mathrm{ft} / \mathrm{s}$. Thus, it had already sustained minor damage prior to the $8-\mathrm{ft} / \mathrm{s}$ impact. Conversely, testing of the final skid gear redesign testing began with a pristine test article at $8-\mathrm{ft} / \mathrm{s}$. The other major source for difference in the peak accelerations is attributed to the change between the initial and final skid gear design. Based on lessons learned from the first series of tests, the skid gear was modified, resulting in improved impact performance of the design.

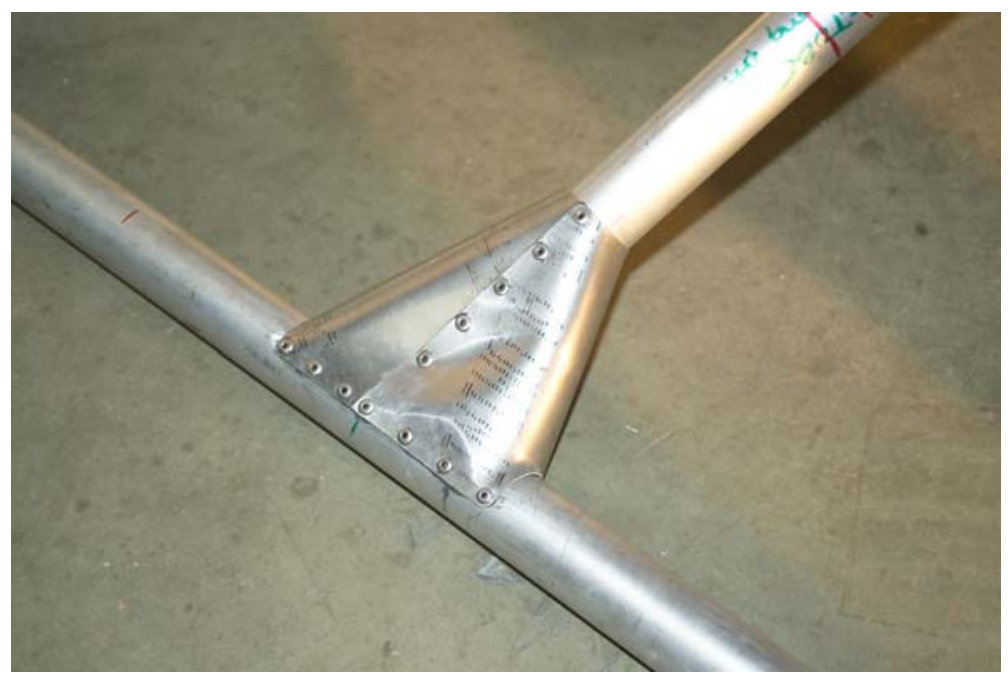

Figure 13. Photograph showing buckling failures of the metal saddle.

\section{Acceleration, $g$}

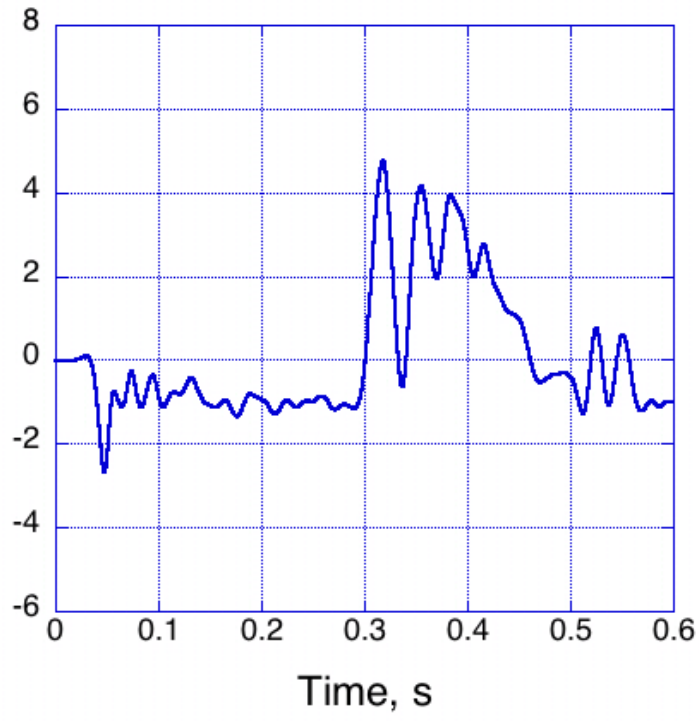

(a) Bottom center of steel plate.
Acceleration, $g$

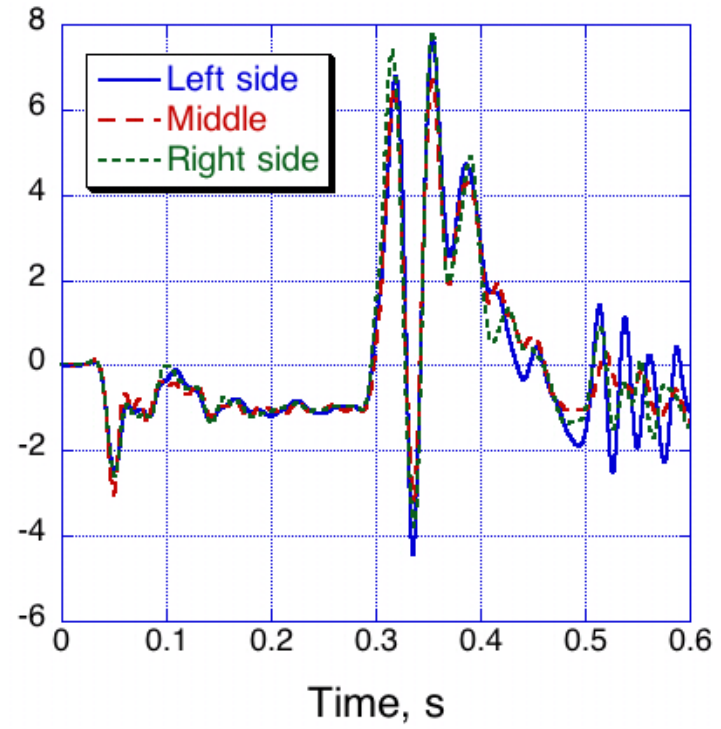

(b) Seating platform.

Figure 14. Acceleration responses from the 8.35-ft/s drop test of the final skid gear design. 
Comparisons of the filtered vertical acceleration responses of the head, chest, and pelvis of the right and left ATD dummy occupants are shown in Figure 15 for the $8.35-\mathrm{ft} / \mathrm{s}$ drop test of the final skid gear design. The peak magnitudes of the acceleration responses range from 6- to 9-g. However, these responses are similar to those obtained during the $8-\mathrm{ft} / \mathrm{s}$ vertical drop test of the initial skid gear redesign, shown in Figure 11. As noted previously, the acceleration responses of the head have the lowest magnitude (6-g) and the pelvic acceleration responses have the highest magnitude (9-g). Some minor differences are seen between the ATD-1 and ATD-2 acceleration responses for the head and chest; however, both curves have similar magnitudes. ATD-2 exhibits a higher peak acceleration of 9-g in the pelvis, than seen for ATD-1 (8-g).

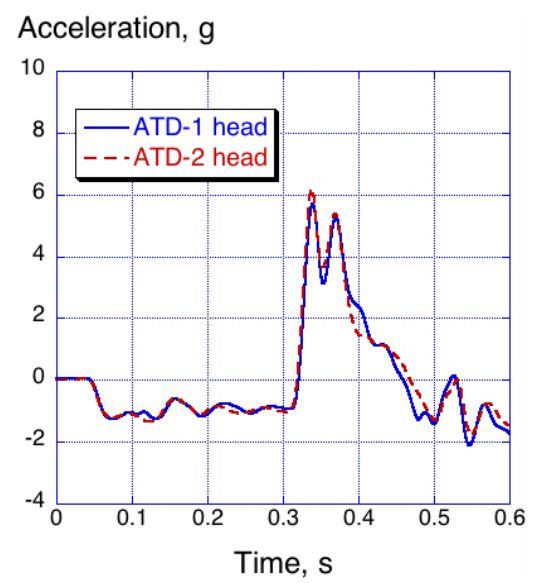

(a) Head.

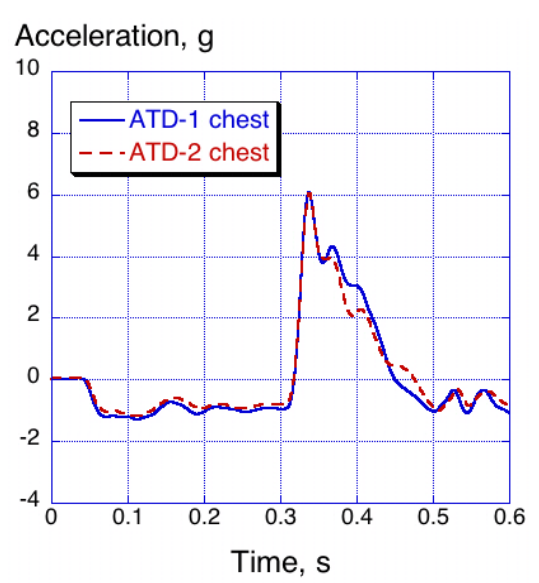

(b) Chest.

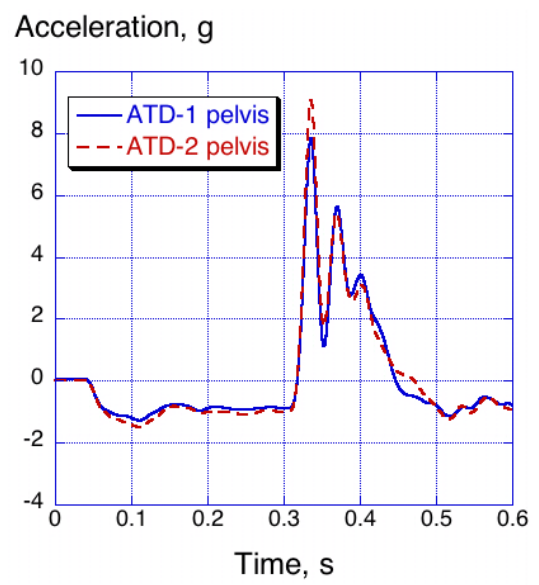

(c) Pelvis.

Figure 15. Occupant acceleration responses during the $8.35-\mathrm{ft} / \mathrm{s}$ vertical drop test of the final skid gear design.

\section{Test Results: 10.0-ft/s Vertical Drop Test}

Based on the relatively minor damage that occurred to the test article during the $8.35-\mathrm{ft} / \mathrm{s}$ vertical velocity drop test, a decision was made to go forward with the $10-\mathrm{ft} / \mathrm{s}$ drop test. This test was performed by lifting the test article to the designated drop height of 18.6-inches, then releasing the test article to impact a smooth concrete surface.

A pre-test photo of the test article in the release position is shown in Figure 16(a) and a post-test photo is shown in Figure 16(b). For the 10-ft/s drop test condition, the gear did not collapse. However, additional damage to the skid gear was incurred. Damage modes included severe buckling of the metal saddles surrounding the strut attachments to the skid beams, metal tearing, and rivet line failures. These damage modes are depicted in Figure 17, which shows some close up photos of the test article. FAR $\$ \$ 27.723,27.725$, and 27.727 on Landing Gear Shock Absorption Tests state [2]:

"The landing inertia load factor and the reserve energy absorption capacity of the landing gear must be substantiated by the tests prescribed in $\$ \S 27.725$ and 27.727 , respectively. ... The limit drop test must be conducted as follows: (a) The drop height must be - (1) 13 inches from the lowest point of the landing gear to the ground; ... The reserve energy absorption drop test must be conducted as follows: (a) The drop height must be 1.5 times that specifies in $\$ 27.725(a) . .$. (c)The landing gear must withstand this test without collapsing." 
These test results, along with the favorable results from the previous 8.35 -ft/s drop test, indicate that the modified skid gear would meet the certification requirements for landing loads specified in FAR 27.

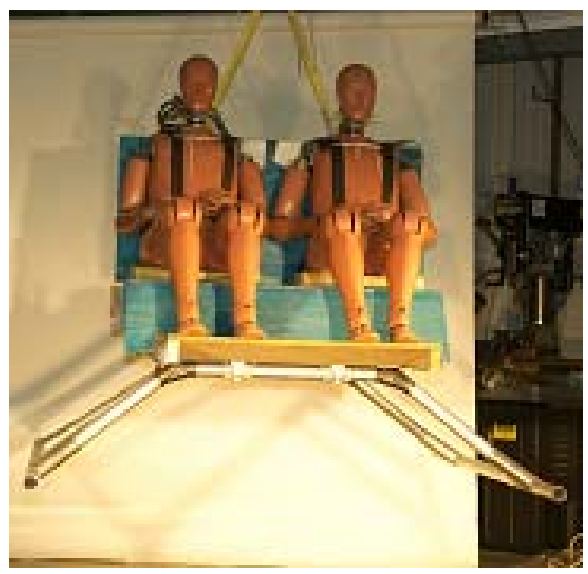

(a) Pre-test photo.

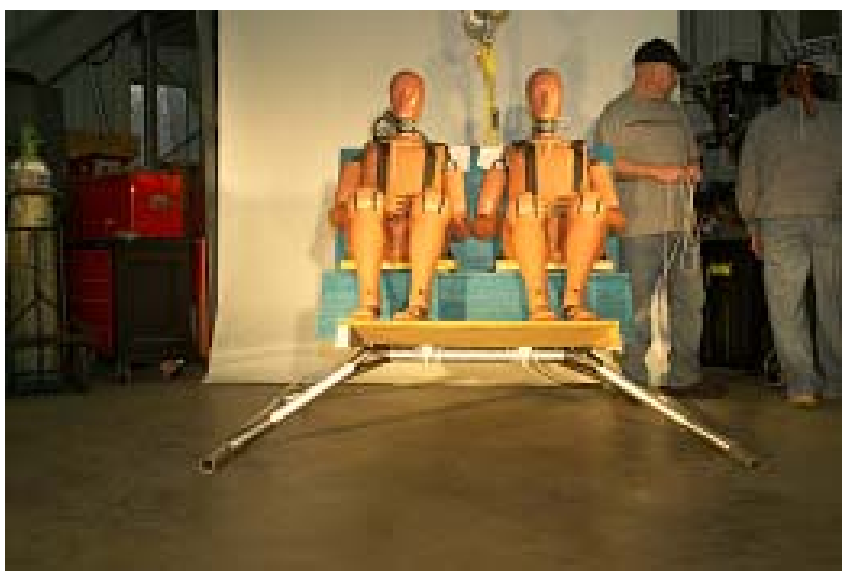

(b) Post-test photo.

Figure 16. Pre- and post-test photos of the final skid gear design for the $10-\mathrm{ft} / \mathrm{s}$ vertical drop test.

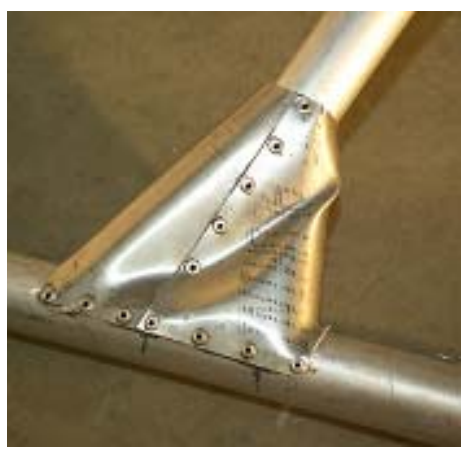

(a) Buckling of the saddle.

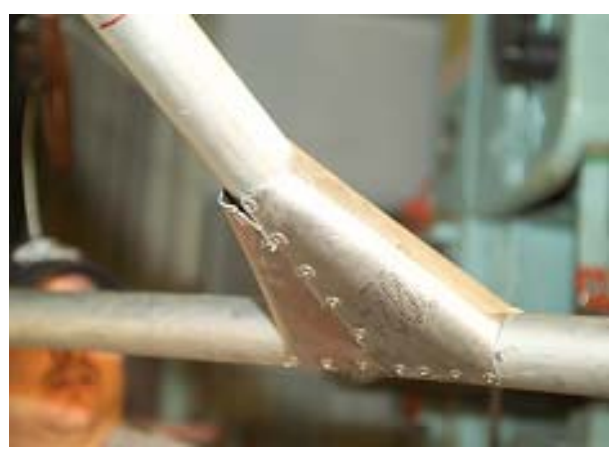

(b) Metal tearing.

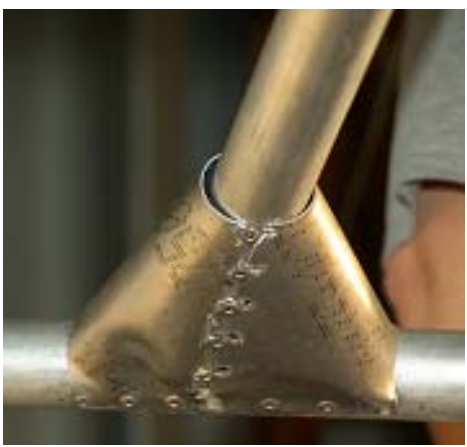

(c) Rivet line failure.

Figure 17. Photographs illustrating the damage modes during the $10-\mathrm{ft} / \mathrm{s}$ vertical drop test.

Acceleration responses from the steel plate and seating platform are shown in Figures 18(a) and (b) respectively, for the 10-ft/s vertical drop test. For this impact condition, the peak acceleration of the steel plate was $5.2 \mathrm{~g}$, which is still lower than the peak acceleration (5.4-g) obtained during the $8-\mathrm{ft} / \mathrm{s}$ vertical drop of the initial skid gear redesign. The acceleration response exhibited three distinct peaks with the second peak having the higher magnitude. The vertical acceleration responses of the left side, middle, and right side of the seating platform are shown in Figure 18(b). The three curves are nearly identical, however the left side response has the highest peak of $8.1 \mathrm{~g}$.

Comparisons of the filtered vertical acceleration responses of the head, chest, and pelvis of the right and left ATD dummy occupants are shown in Figure 19 for the 10-ft/s drop test of the final skid gear design. The peak magnitudes of the acceleration responses shown in Figure 19 range from 6.9- to 9-g. As noted previously, the acceleration responses of the head have the lowest magnitude (6.9-g) and the pelvic acceleration responses have the highest magnitude (9-g). Only minor differences are seen between the ATD-1 and ATD-2 acceleration responses; however, the 
pelvis acceleration of ATD-2 is slightly higher in magnitude than the ATD-1 response. No visible crushing of either seat foam filler was observed post-test.

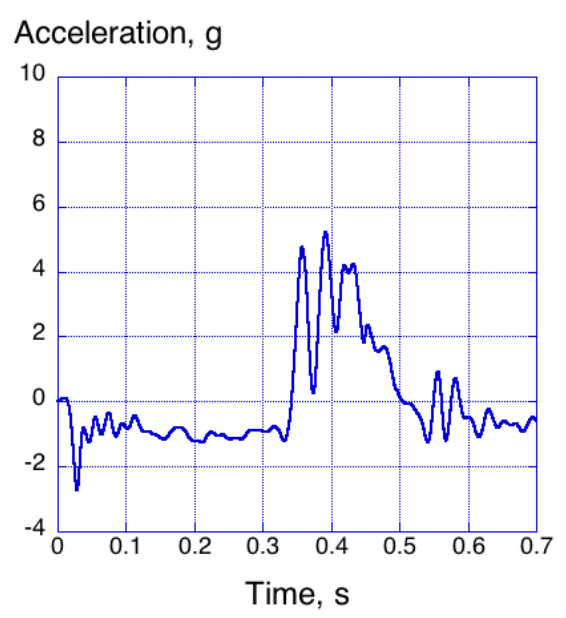

(a) Bottom center of the steel plate.

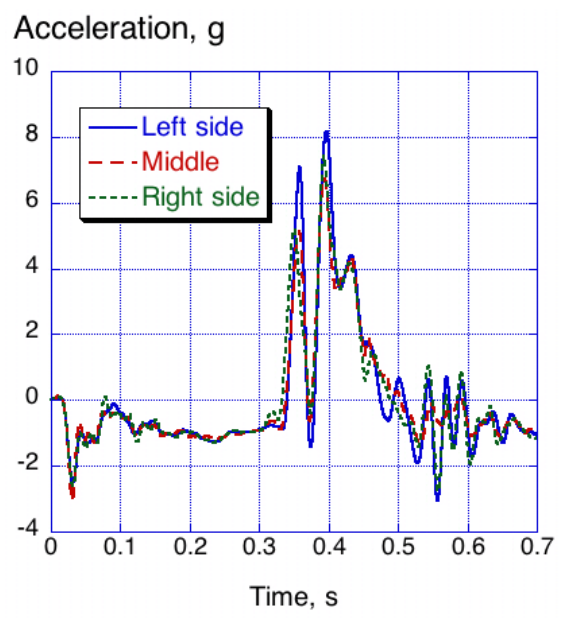

(b) Seat platform.

Figure 18. Acceleration responses from the 10-ft/s vertical drop test of the final skid gear design.

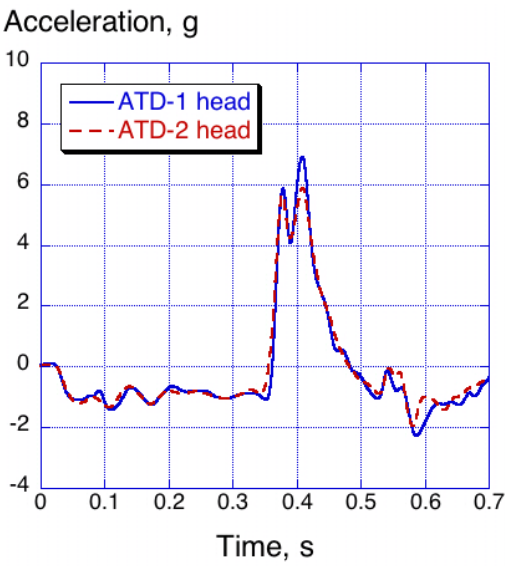

(a) Head.

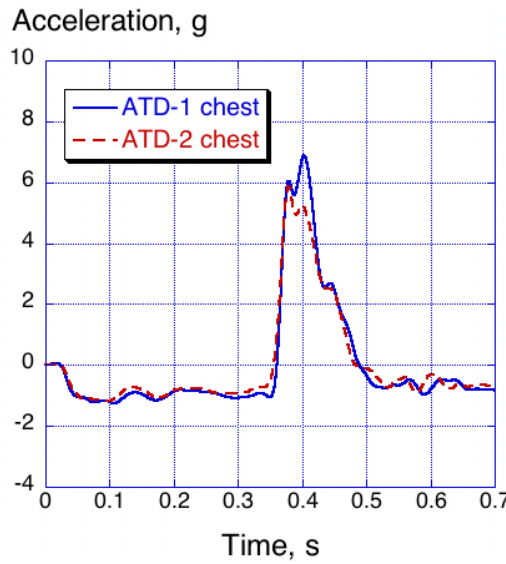

(b) Chest.

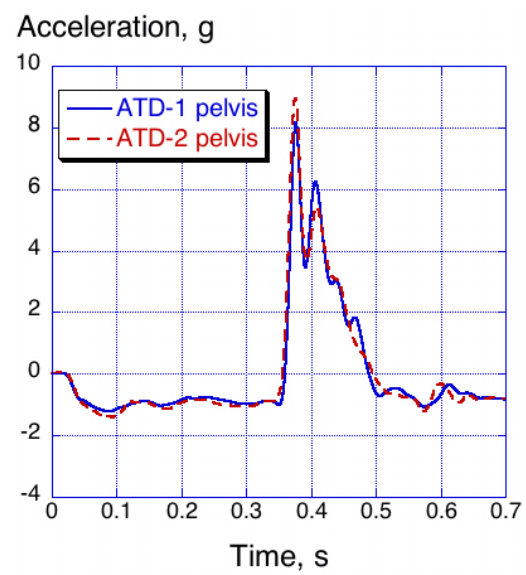

(c) Pelvis.

Figure 19. Comparisons of ATD responses from the 10-ft/s vertical drop test of the final skid gear design.

\section{Test Results: 12.69-ft/s Vertical Drop Test}

Following the $10-\mathrm{ft} / \mathrm{s}$ vertical drop test, a decision was made to conduct the third test in the series at $12.69-\mathrm{ft} / \mathrm{s}$ vertical velocity. This test was risky in that the gear was already damaged; however, the instrumentation was protected from any direct contact with the impact surface. Consequently, a decision was made to go forward with the drop test.

The test article was raised to a height of 30-inches and released to impact a smooth concrete surface. As with the previous tests, 26 channels of data were collected at 50,000 samples per second using a digital data acquisition program. Pre- and post-test photographs of the test article are shown in Figure 20. Both sides of the skid gear collapsed upon impact for this test condition. The gear failed at the attachment of the strut with the crossbeam and at the saddle attachment of the strut to the longitudinal skid beam. These failures are highlighted in Figure 21. 


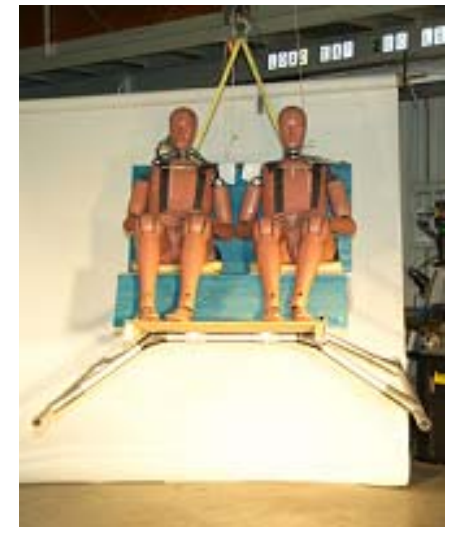

(a) Pre-test photo.

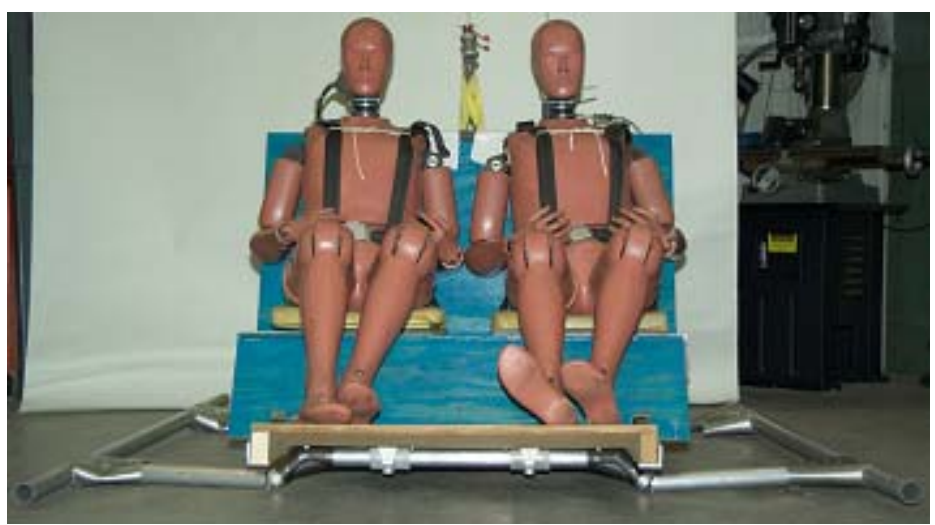

(b) Post-test photo.

Figure 20. Pre- and post-test photographs of the test article for the 12.69-ft/s test.

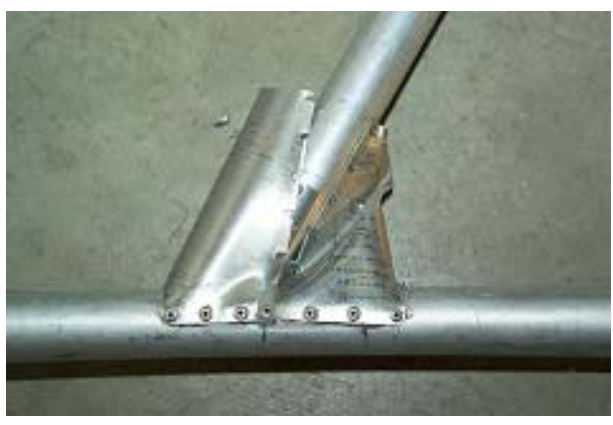

(a) Saddle failure.

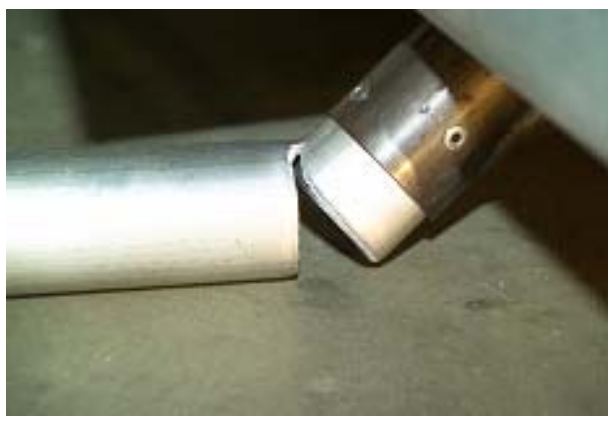

(b) Strut failure.

Figure 21. Photographs of discrete skid gear failures from the 12.69-ft/s drop test.

Acceleration responses are shown in Figure 22 for the bottom center of the steel plate and the left side, middle, and right side of the seating platform for the $12.69-\mathrm{ft} / \mathrm{s}$ vertical drop test of the final skid gear design. These responses are dominated by one high peak of 27.5 -g for the steel plate and 32-g for the seating platform. These values are considerably higher than those obtained from previous drop tests and they reflect the fact that the gear failed on impact allowing the steel plate and seating platform to impact the concrete surface. 
Acceleration, $g$

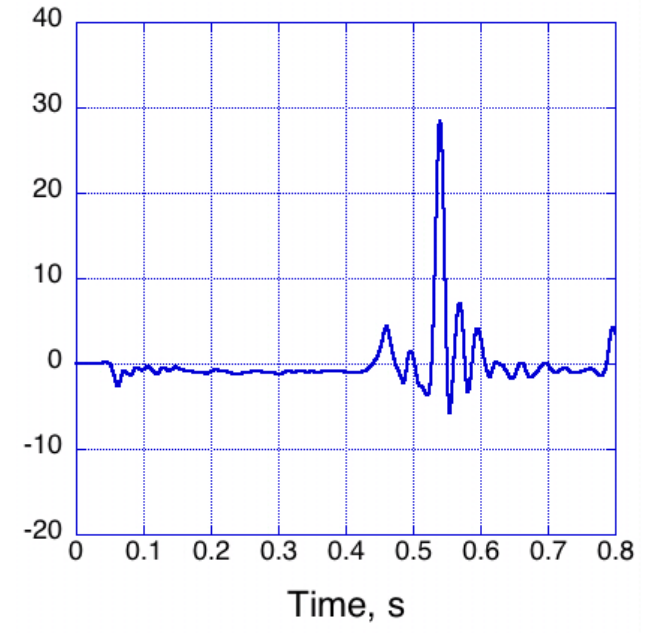

(a) Bottom center of the steel plate.
Acceleration, $\mathrm{g}$

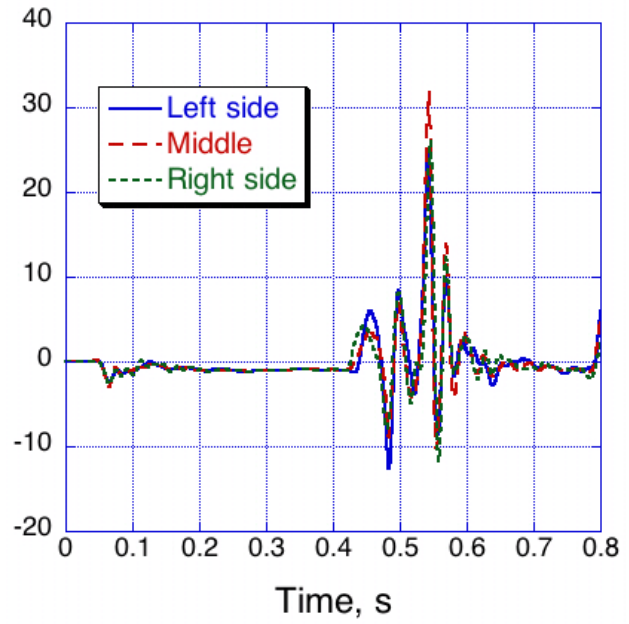

(b) Seating platform.

Figure 22. Test article acceleration responses for the 12.69-ft/s vertical drop test.

Comparisons of the filtered vertical acceleration responses of the head, chest, and pelvis of the right and left ATD dummy occupants are shown in Figure 23 for the 12.69-ft/s drop test of the final skid gear design. The acceleration responses shown in Figure 23 are much higher in magnitude than those seen in the previous drop tests with peak values ranging from 18- to 21-g. Contrary to previous test results, the acceleration responses of the head have the highest magnitude (21-g), while the peaks for the chest and pelvis responses are lower at 18-g. At each location, the ATD-1 responses have a slightly higher magnitude than the ATD-2 responses. No visible crushing of either seat foam filler was observed post-test.

Acceleration, $\mathrm{g}$

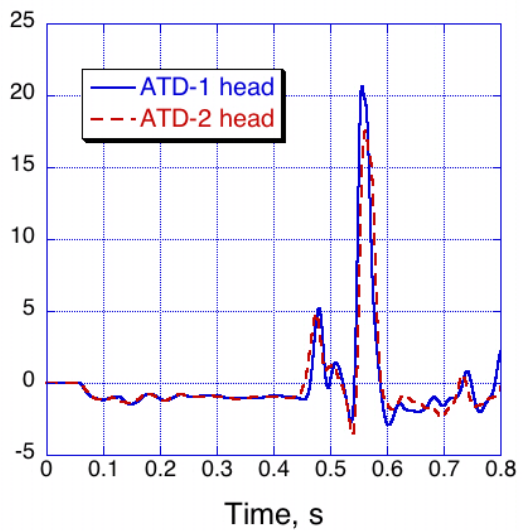

(a) Head.
Acceleration, $\mathrm{g}$

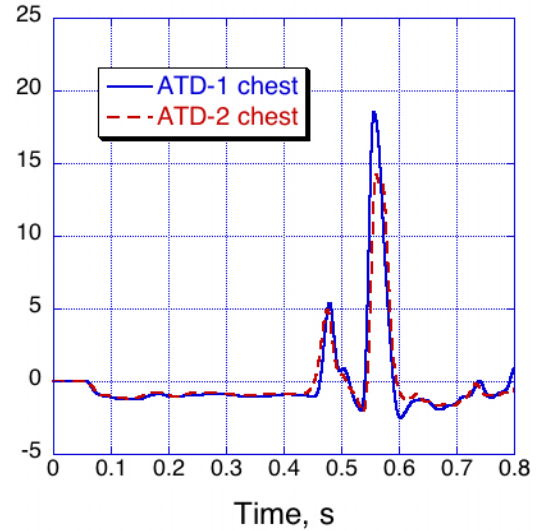

(b) Chest.

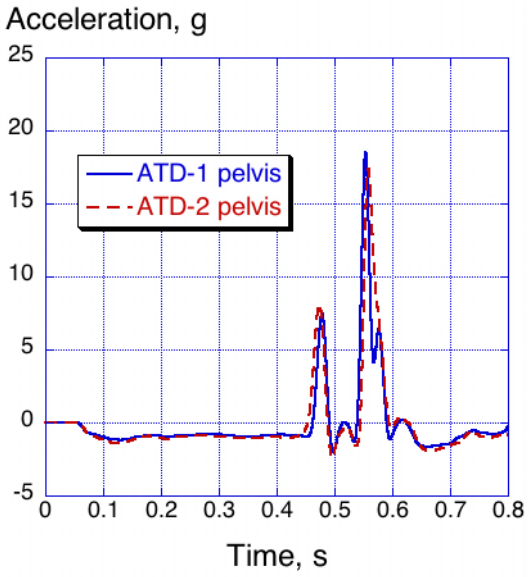

(c) Pelvis.

Figure 23. ATD acceleration responses from the $12.69-\mathrm{ft} / \mathrm{s}$ vertical drop test. 


\section{INJURY ASSESSMENT}

During the three vertical drop tests that were conducted on the final skid gear design each of the $95^{\text {th }}$ percentile male Hybrid III ATDs were instrumented with seven accelerometers (tri-axial accelerometers in the pelvis and chest and one vertical accelerometer in the head). The dynamic acceleration responses obtained from these instruments were used to perform an injury risk assessment. Several methods are typically used to evaluate human injury potential, including the Dynamic Response Index (DRI) [5-7], the Brinkley Index [8, 9], Lumbar Load limits [7], Head Injury Criteria [10,11], and Eiband whole body acceleration tolerance limits $[12,13]$. In this study, occupant injury was evaluated based on the DRI and the Brinkley Index.

\section{A. Dynamic Response Index (DRI)}

The Dynamic Response Index (DRI) [5-7] is derived from a simple one-dimensional lumpedmass spring damper system, as depicted in Figure 24. This model was developed by the Air Force's Wright Laboratory to estimate the probability of compression fractures in the lower spine due to acceleration in a pelvis-to-head direction, as might be experienced by aircrew during seat ejections. Operational data from actual ejection seat incidents indicate that the spinal injury rate for maximum DRI values between 20 and 23 range from 16 to 50 percent $[6,7]$. A plot showing spinal injury rate versus maximum DRI is shown in Figure 25. This plot contains operational data, as well as data calculated from cadaver tests.

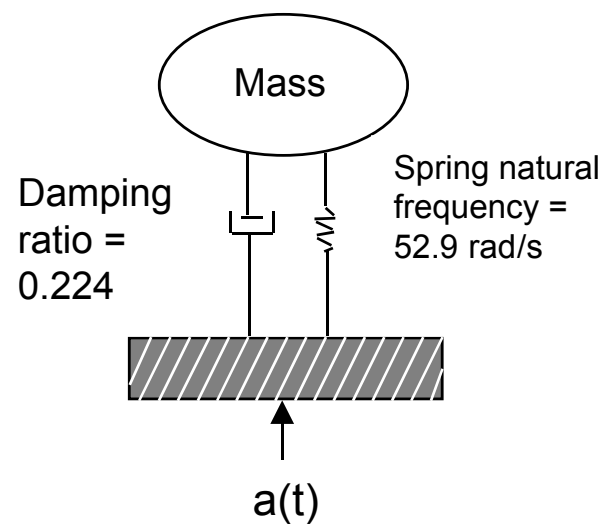

Figure 24. Schematic of the DRI injury model.

Unfiltered vertical acceleration responses of the chest and pelvis of the ATDs were input $(a(t)$ as shown in Figure 24) to compute the DRI time history response (often referred to as the continuous DRI response), which is the dynamic response of the lumped-spring-mass system depicted in Figure 24. Comparisons of the input acceleration responses (raw data) and the continuous DRI are plotted for both dummies in each vertical drop test of the final skid gear design. The maximum value of DRI is shown in the plot legend.

\subsection{5-ft/s Vertical Drop Test}

The chest and pelvis acceleration responses are plotted versus the computed continuous DRI responses for ATD-1 and ATD-2 in Figures 26 and 27, respectively, for the 8.35-ft/s vertical drop test of the final skid gear design. The maximum DRI recorded for either of these two dummies is $7.49-\mathrm{g}$. This value is well below the lowest level indicative of injury, as indicated in Figure 25. 


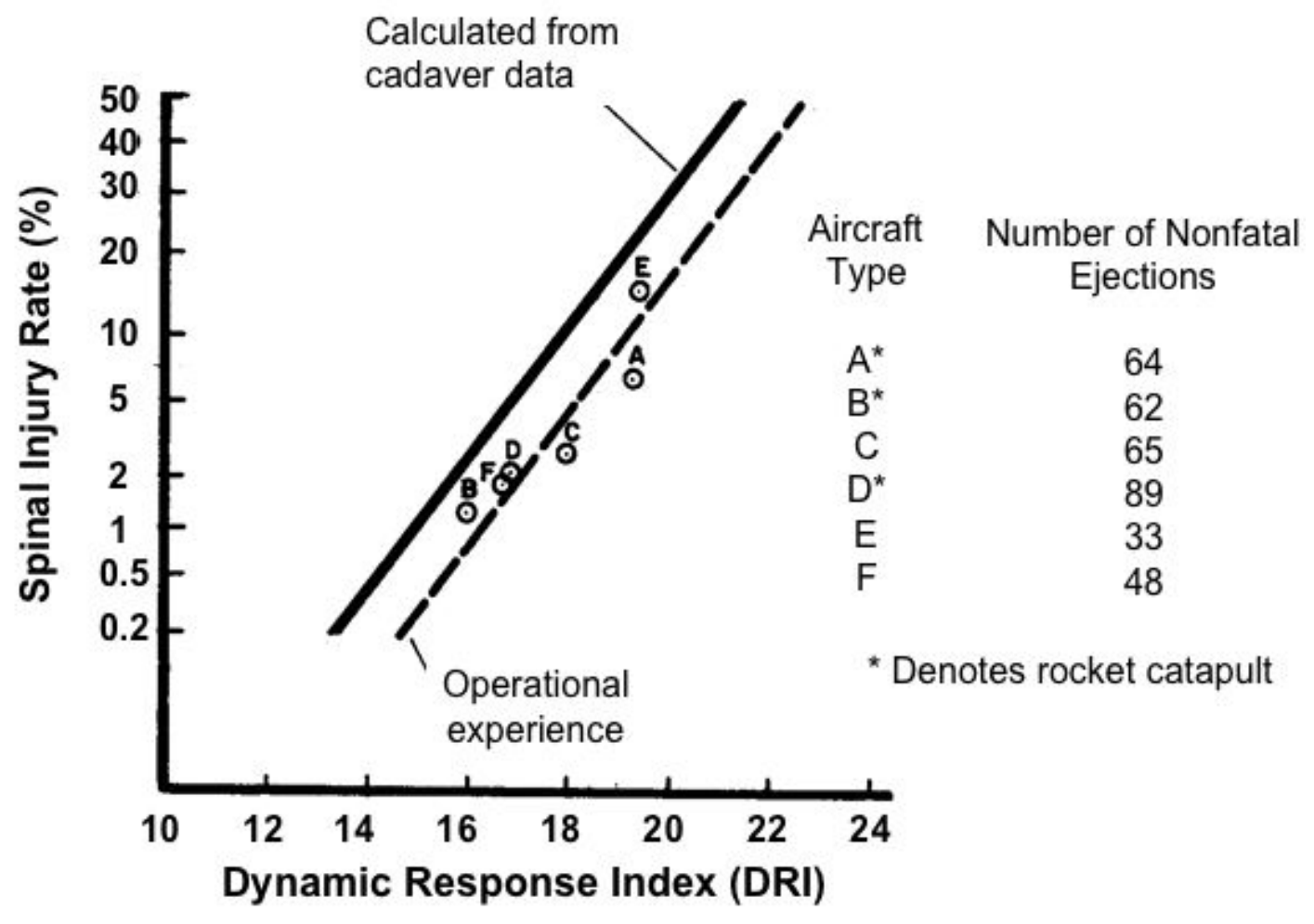

Figure 25. Plot of spinal injury rate versus maximum DRI.

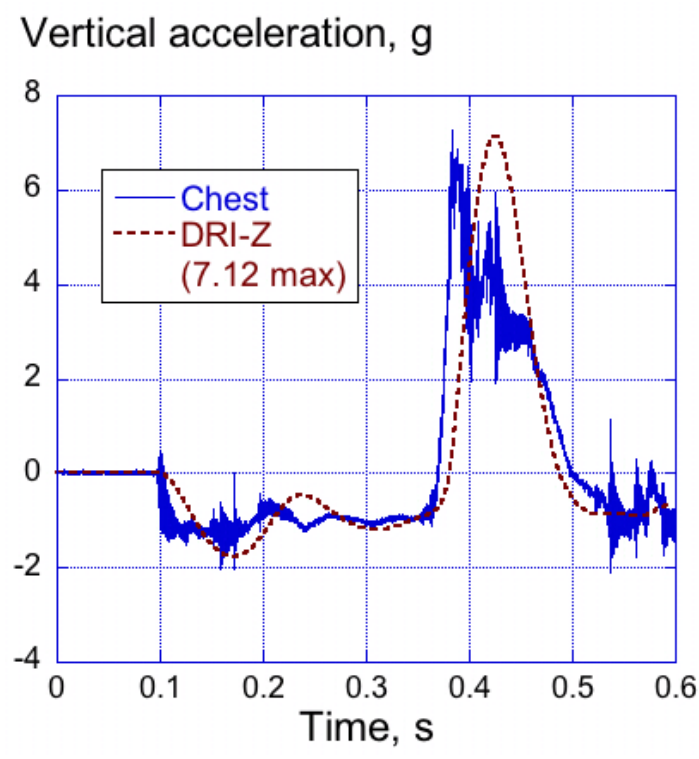

(a) Chest responses.

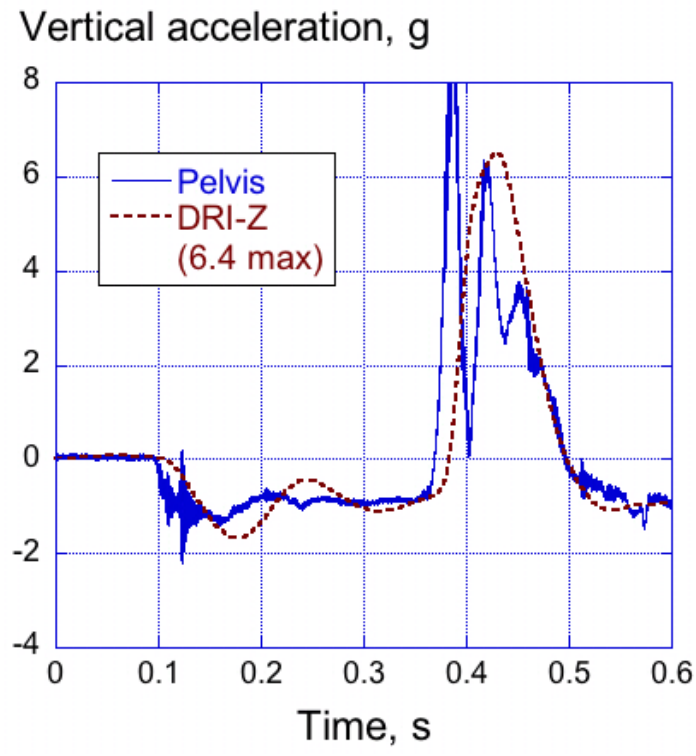

(b) Pelvis responses

Figure 26. ATD-1 acceleration and continuous DRI responses for the $8.35-\mathrm{ft} / \mathrm{s}$ test. 
Vertical Acceleration, $g$

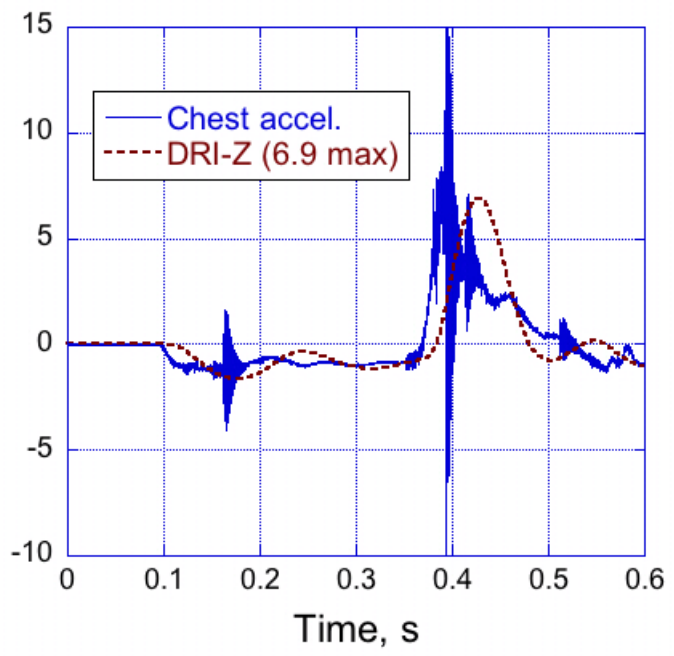

(a) Chest responses.
Vertical Acceleration, $g$

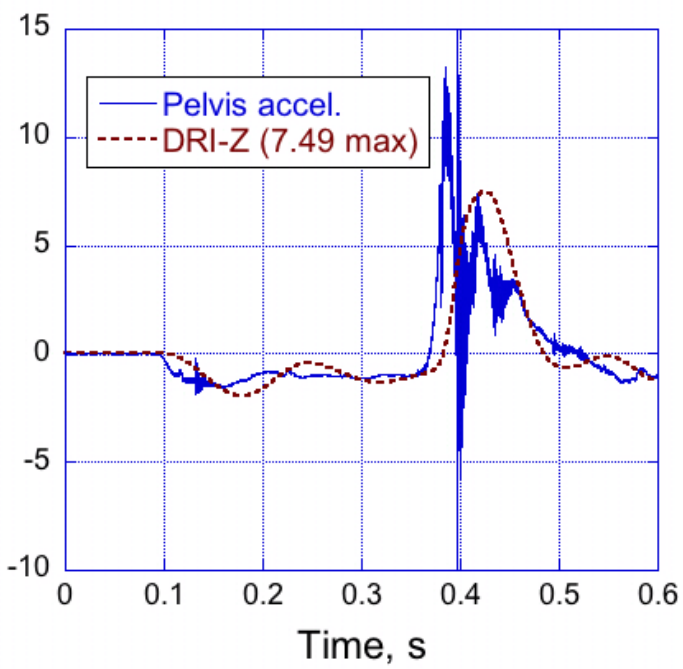

(b) Pelvis responses

Figure 27. ATD-2 acceleration and continuous DRI responses for the $8.35-\mathrm{ft} / \mathrm{s}$ test.

\section{0-ft/s Vertical Drop Test}

The chest and pelvis acceleration responses are plotted versus the computed continuous DRI responses for ATD-1 and ATD-2 in Figures 28 and 29, respectively, for the 10.0-ft/s vertical drop test of the final skid gear design. The maximum DRI recorded for either of these two dummies is 9.3-g. As expected, this value is higher than the maximum DRI obtained from the $8.35-\mathrm{ft} / \mathrm{s}$ vertical drop test. However, this value is still below the lowest level indicative of injury (see Figure 25).

Vertical Acceleration, $g$

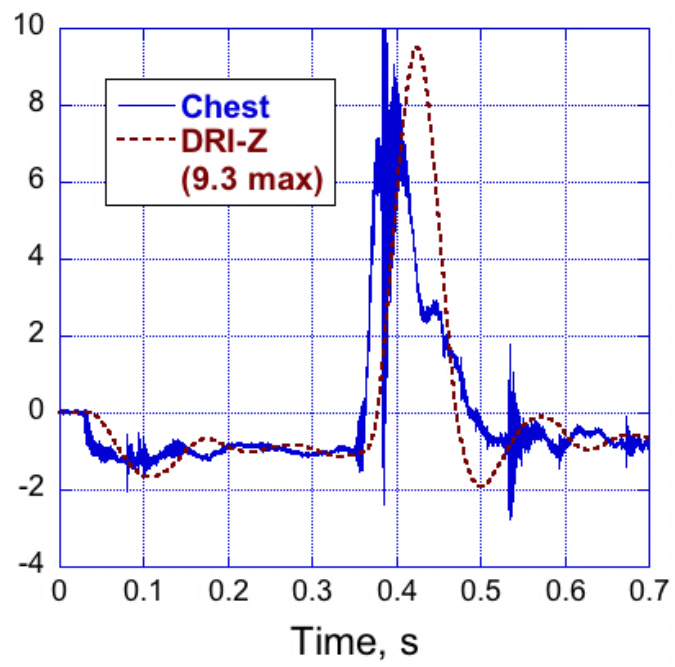

(a) Chest responses.
Vertical Acceleration, $g$

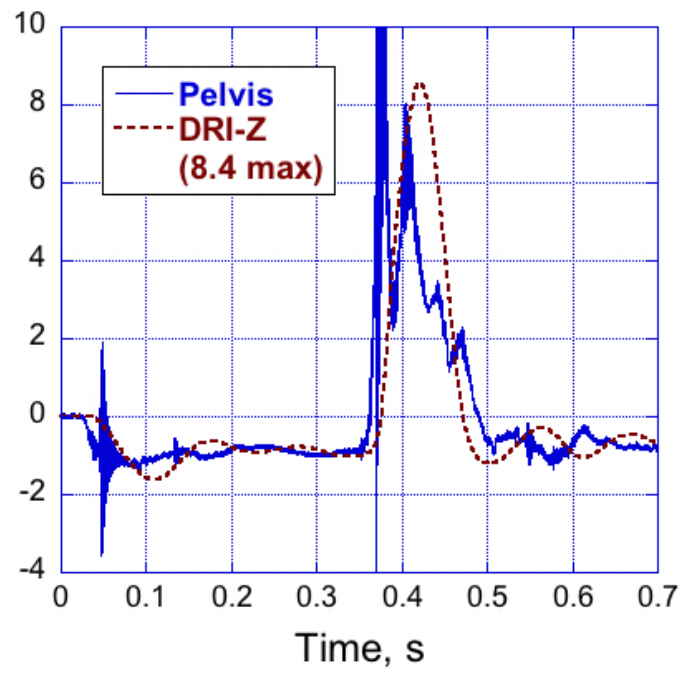

(b) Pelvis responses

Figure 28. ATD-1 acceleration and continuous DRI responses for the $10-\mathrm{ft} / \mathrm{s}$ test. 
Vertical Acceleration, $g$

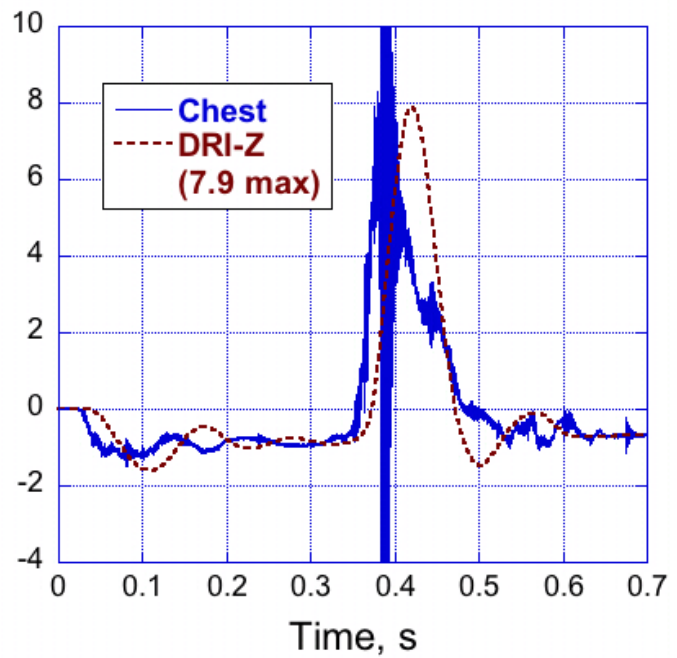

(a) Chest responses.
Vertical Acceleration, g

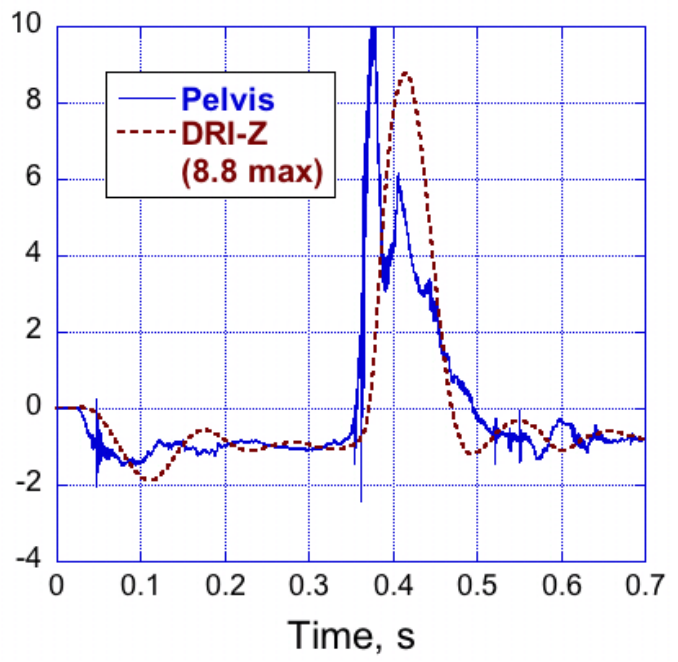

(b) Pelvis responses

Figure 29. ATD-2 acceleration and continuous DRI responses for the $10-\mathrm{ft} / \mathrm{s}$ test.

\subsection{9-ft/s Vertical Drop Test}

The chest and pelvis acceleration responses are plotted versus the computed continuous DRI responses for ATD-1 and ATD-2 in Figures 30 and 31, respectively, for the $12.69-\mathrm{ft} / \mathrm{s}$ vertical drop test of the final skid gear design. The maximum DRI recorded for either of these two dummies is 15.4-g. Again, this value is higher than the maximum DRI obtained from either the 8.35-or the 10.0-ft/s vertical drop tests. However, this value falls within the lower limit for injury. Operational data from actual ejection seat incidents indicate that the spinal injury rate for a maximum DRI value of 15.4 is less than $0.5 \%$ percent (see Figure 25 ).

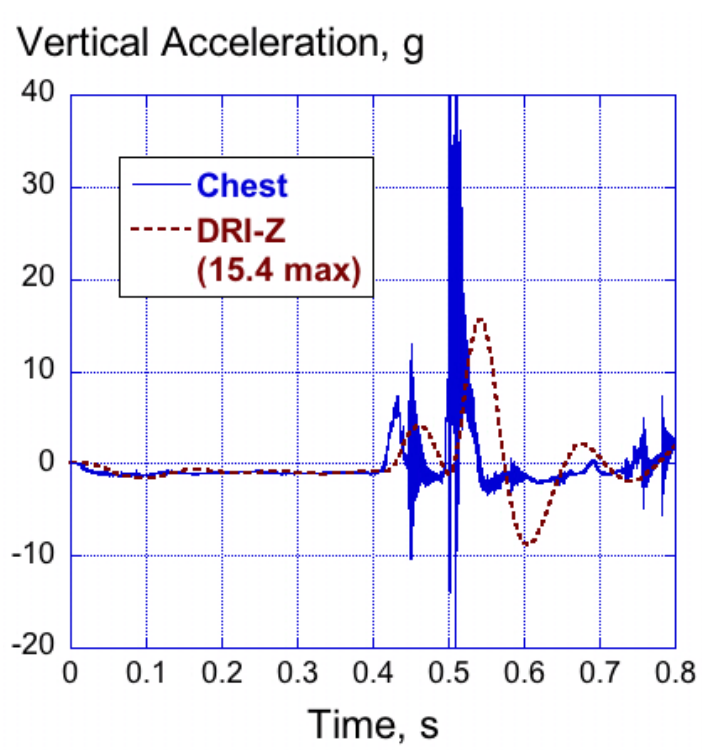

(a) Chest responses.

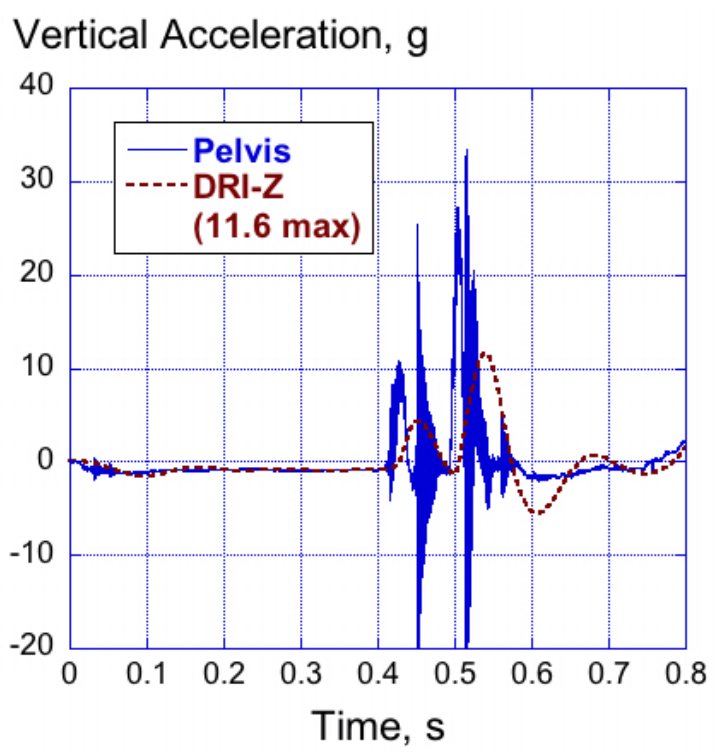

(b) Pelvis responses

Figure 30. ATD-1 acceleration and continuous DRI responses for the $12.69-\mathrm{ft} / \mathrm{s}$ test. 


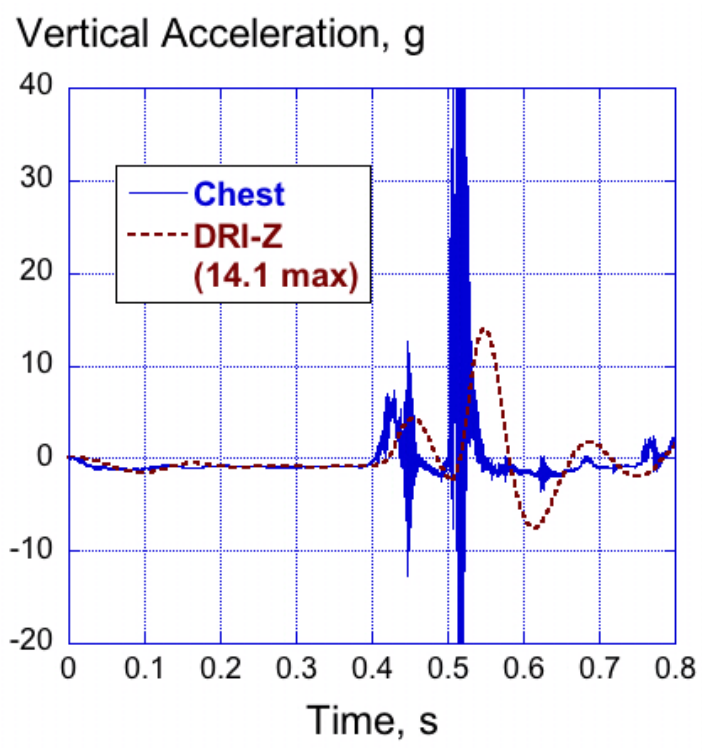

(a) Chest responses.
Vertical Acceleration, $g$

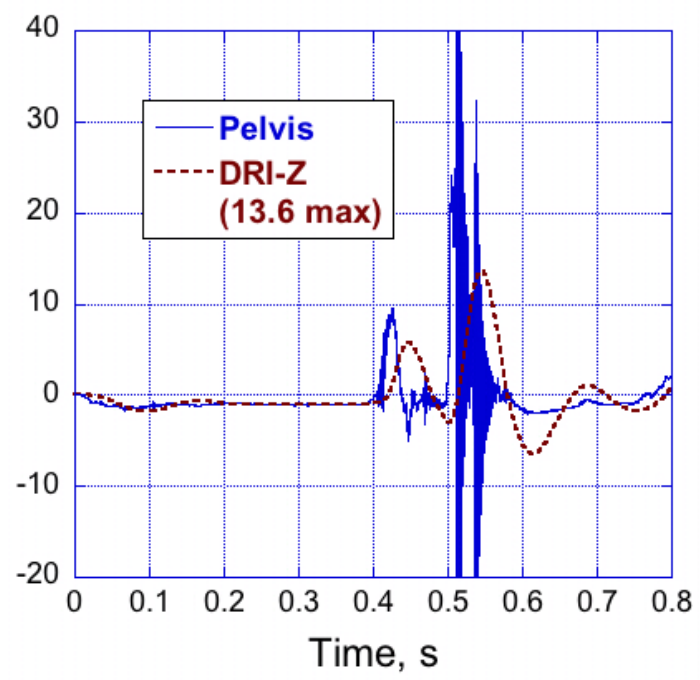

(b) Pelvis responses

Figure 31. ATD-2 acceleration and continuous DRI responses for the $12.69-\mathrm{ft} / \mathrm{s}$ test.

\section{B. Brinkley Index}

The one-dimensional DRI model has obvious limitations for application to impact scenarios involving multi-directional acceleration components. Thus, the Brinkley Index [8] was developed to account for acceleration components in the three orthogonal axes on the human occupant. A FORTRAN program DYNRESP [9], obtained from NASA Johnson Space Center, was used to calculate the dynamic response and injury risk assessment of a seated occupant by analyzing the measured $\mathrm{x}, \mathrm{y}$, and $\mathrm{z}$ linear accelerations. Typically, the multi-directional seat pan accelerations are used in the calculations. However, since the skid gear test article was not configured with typical aircraft seats, the tri-axial pelvis and chest acceleration responses were used for this assessment.

For the Brinkley Index, the dynamic response of the occupant is represented using multidirectional mass, spring, and damper systems. Each orthogonal axis is modeled with a different spring-damper representation. The general risk of injury is determined based on the combined dynamic responses of the three axes and the defined limits in these directions using Equation 1:

$$
\beta=\left[\left(\frac{D R X}{D X_{L}}\right)^{2}+\left(\frac{D R Y}{D R Y_{L}}\right)^{2}+\left(\frac{D R Z}{D R Z_{L}}\right)^{2}\right]^{1 / 2}
$$

where DRX, DRY, and DRZ are the dynamic responses for the $\mathrm{x}-, \mathrm{y}-$, and z-axes; $\mathrm{DRX} \mathrm{L}_{\mathrm{L}}, \mathrm{DRY}_{\mathrm{L}}$, and $\mathrm{DRZ}_{\mathrm{L}}$ are the limit values defined for low, moderate, and high risk, and $\beta$ is the injury-risk criterion. Different dynamic response limit values, listed in Table 1, are used for low, moderate, and high risk [8]. Risk levels for injury are considered acceptable if $\beta$ is less than 1 . The Brinkley Index was applied by inputting the tri-axial components of acceleration obtained from the pelvis and chest of each ATD into the model described by Equation 1 for each vertical drop test. 
Table 1. Dynamic Response Limit Values for Low, Moderate, and High Risk

\begin{tabular}{|c|c|c|c|c|c|c|}
\hline & \multicolumn{2}{|c|}{$\mathrm{DRX}_{\mathrm{L}}$} & \multicolumn{2}{c|}{$\mathrm{DRY}_{\mathrm{L}}$} & \multicolumn{2}{c|}{$\mathrm{DRZ}_{\mathrm{L}}$} \\
\cline { 2 - 7 } & $\mathrm{DRX}>0$ & $\mathrm{DRX}<0$ & $\begin{array}{c}\text { Conventional } \\
\text { restraint }\end{array}$ & $\begin{array}{c}\text { Side } \\
\text { panels }\end{array}$ & DRZ $>0$ & $\mathrm{DRZ}<0$ \\
\hline Low risk & 35 & 28 & 14 & 15 & 15.2 & 13.4 \\
\hline Moderate risk & 40 & 35 & 17 & 20 & 18 & 16.5 \\
\hline High risk & 46 & 46 & 22 & 30 & 22.8 & 20.4 \\
\hline
\end{tabular}

\section{$\underline{8.35-\mathrm{ft} / \mathrm{s} \text { Vertical Drop Test }}$}

The low, medium, and high risk Brinkley Index curves are plotted in Figures 32 and 33 for the chest and pelvis of ATD-1 and ATD-2, respectively, based on the test data obtained during the $8.35-\mathrm{ft} / \mathrm{s}$ vertical drop test of the final skid gear design. As a reminder, risk levels for injury are considered acceptable if $\beta$ is less than 1. None of the curves shown in Figures 32 and 33 has a magnitude of $\beta$ greater than 1.0.

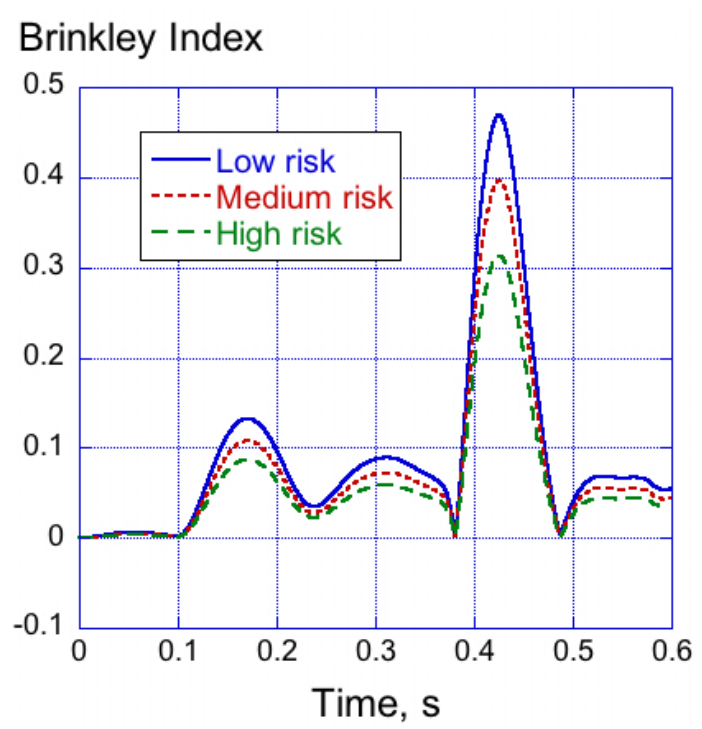

(a) Chest responses.

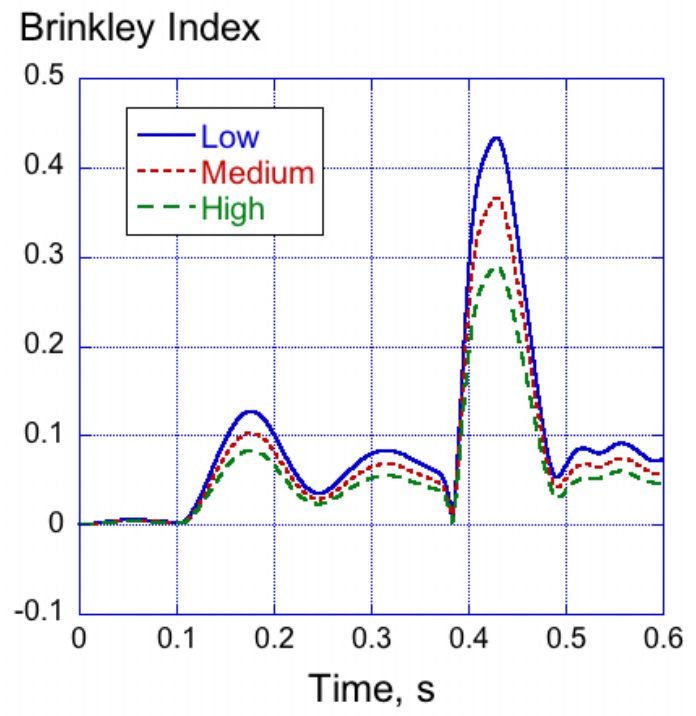

(b) Pelvis responses

Figure 32. ATD-1 Brinkley Indices for the $8.35-\mathrm{ft} / \mathrm{s}$ test. 


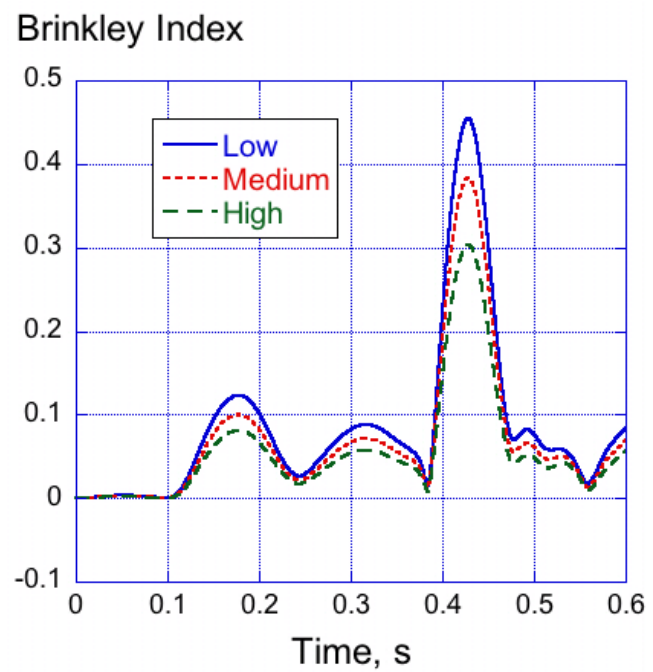

(a) Chest responses.
Brinkley Index

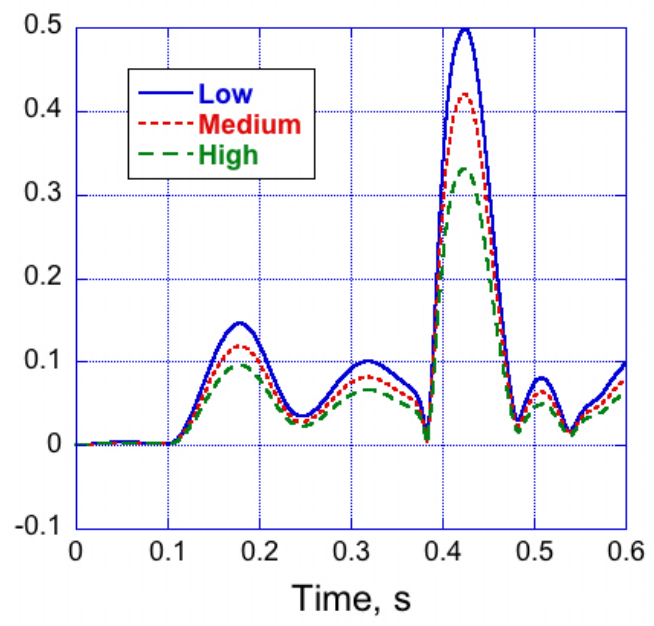

(b) Pelvis responses

Figure 33. ATD-2 Brinkley Indices for the $8.35-\mathrm{ft} / \mathrm{s}$ test.

10.0-ft/s Vertical Drop Test

The low, medium, and high risk Brinkley Index curves are plotted in Figures 34 and 35 for the chest and pelvis of ATD-1 and ATD-2, respectively, based on the test data obtained during the $10.0-\mathrm{ft} / \mathrm{s}$ vertical drop test of the final skid gear design. As expected, the magnitudes of the lowrisk curves are slightly higher than for the $8.35-\mathrm{ft} / \mathrm{s}$ vertical drop test. However, none of the curves shown in Figures 34 and 35 has a magnitude of $\beta$ greater than 1.0.

\section{Brinkley Index}

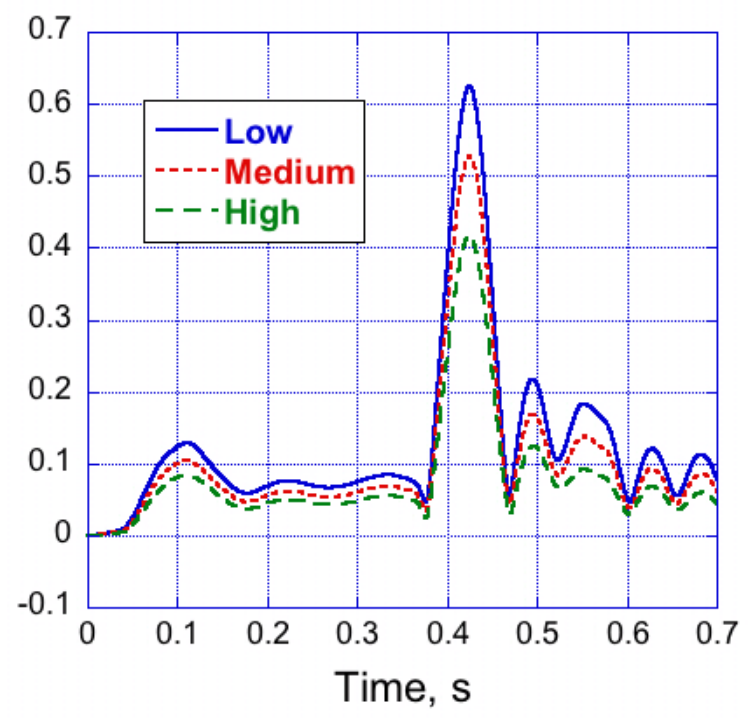

(a) Chest responses.

\section{Brinkley Index}

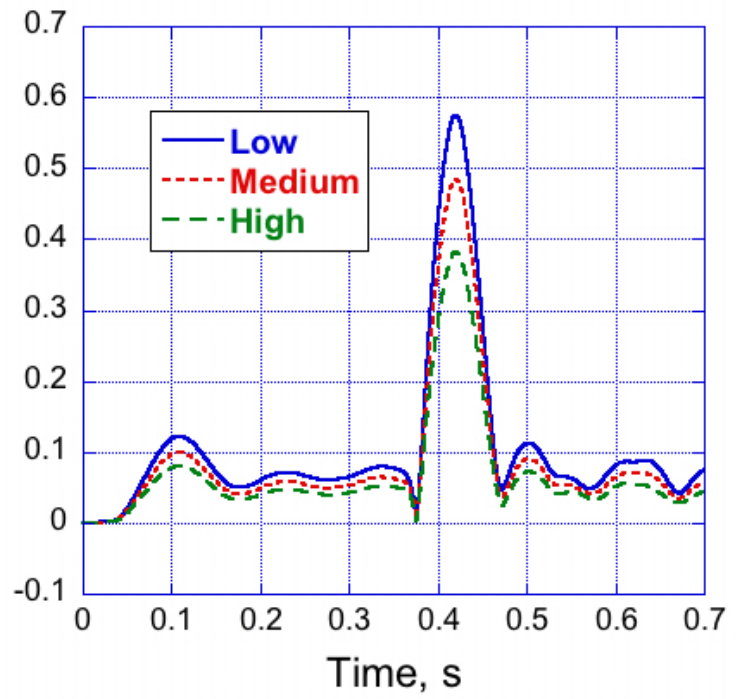

(b) Pelvis responses

Figure 34. ATD-1 Brinkley Indices for the 10.0-ft/s test. 
Brinkley Index

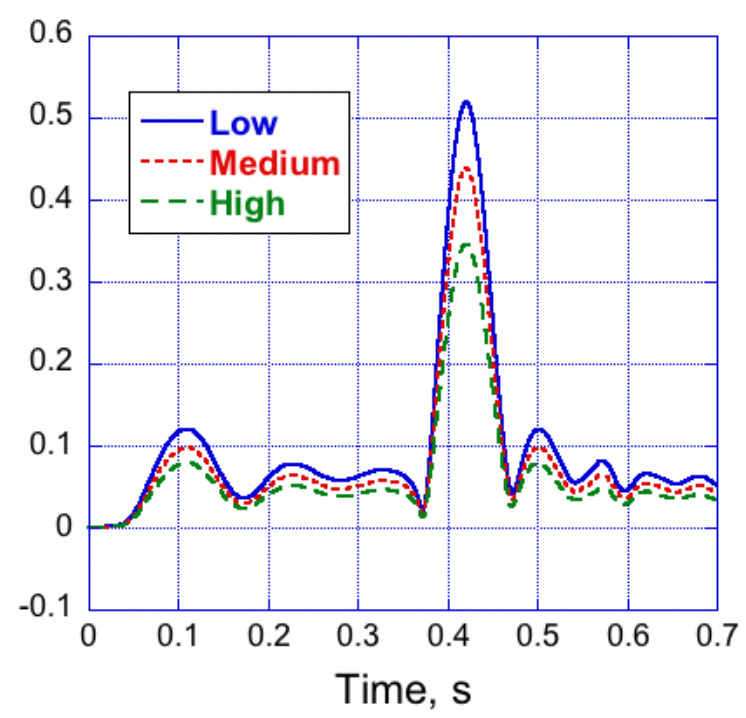

(a) Chest responses.
Brinkley Index

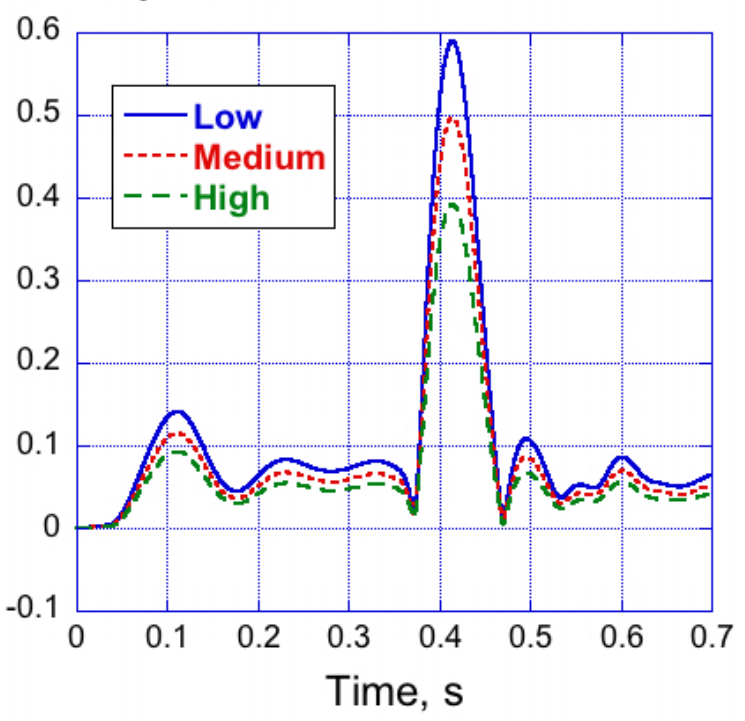

(b) Pelvis responses

Figure 35. ATD-2 Brinkley Indices for the 10.0-ft/s test.

\subsection{9-ft/s Vertical Drop Test}

The low, medium, and high risk Brinkley Index curves are plotted in Figures 36 and 37 for the chest and pelvis of ATD-1 and ATD-2, respectively, based on the test data obtained during the $12.69-\mathrm{ft} / \mathrm{s}$ vertical drop test of the final skid gear design. Again, the overall magnitudes of the Brinkley Indices are higher than for the two previous vertical drop tests. Of particular interest is the fact that the low-risk curve for the ATD-1 chest exceeds 1.0. Based on this result, the injury risk potential would be classified as between low and medium, or between $0.5 \%$ and $5 \%$. All other Brinkley Index curves shown in Figures 36 and 37 are lower than 1.0 in magnitude, indicating that the risk of injury is acceptable.

\section{Brinkley Index}

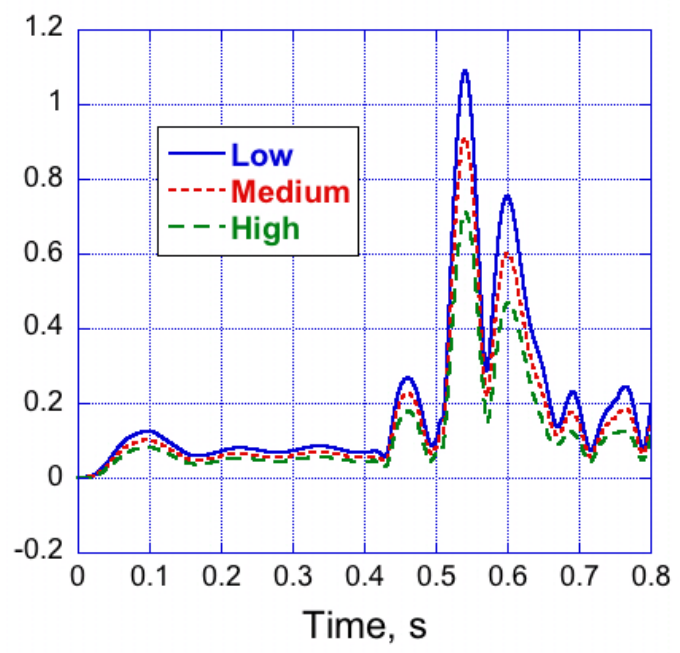

(a) Chest responses.

\section{Brinkley Index}

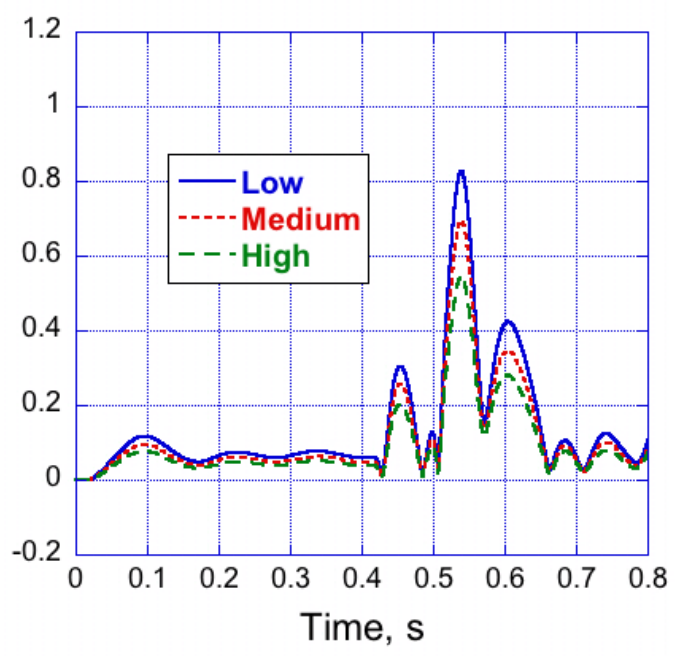

(b) Pelvis responses

Figure 36. ATD-1 Brinkley Indices for the 12.69-ft/s test. 
Brinkley Index

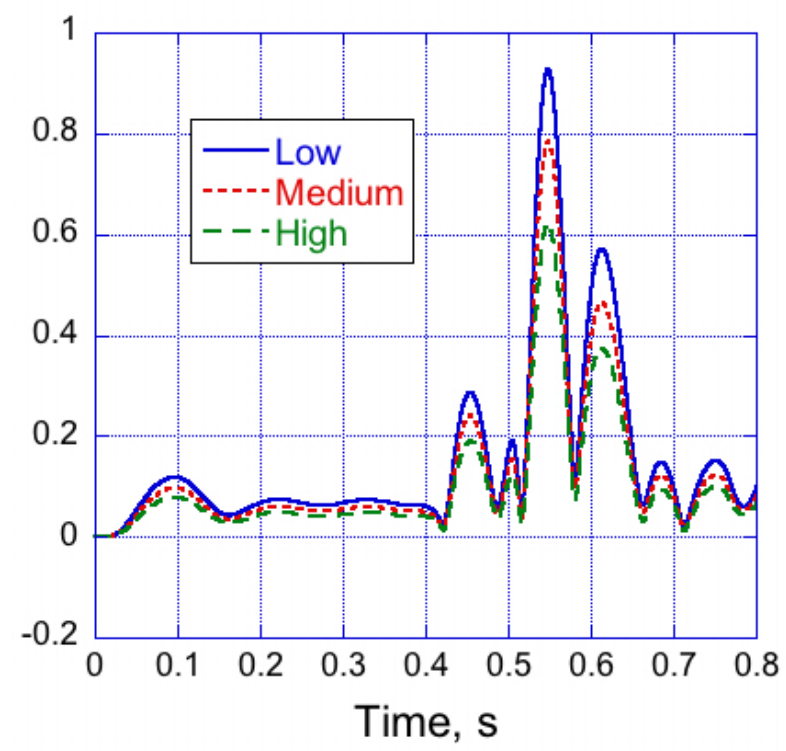

(a) Chest responses.

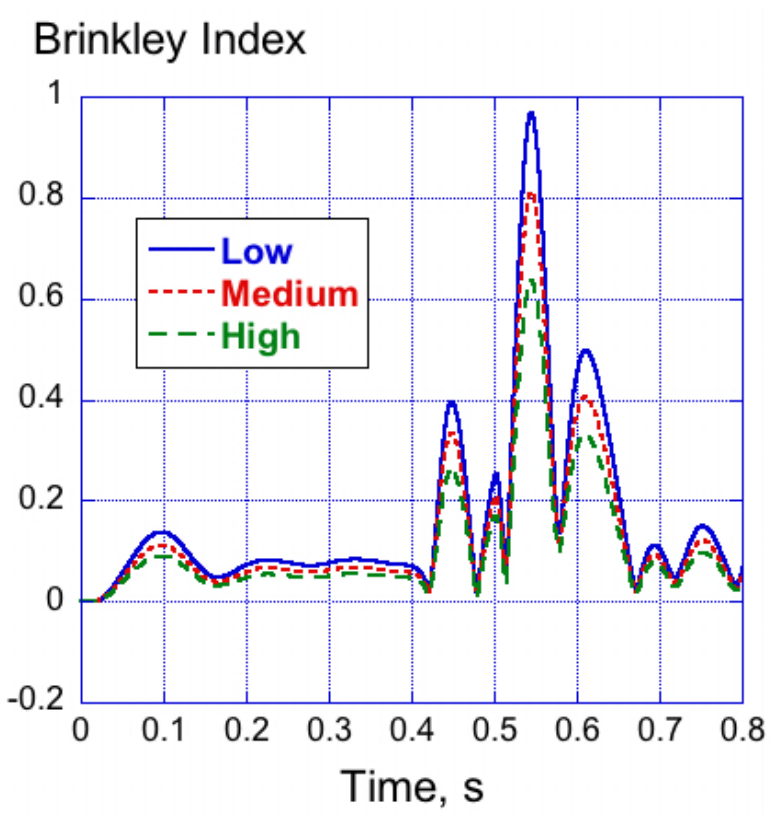

(b) Pelvis responses

Figure 37. ATD-2 Brinkley Indices for the 12.69-ft/s test.

The findings of the injury risk assessment are that the potential of injury for each of the three impact test conditions is extremely low. The maximum value of DRI obtained was 15.4. Operational data from actual ejection seat incidents indicate that the spinal injury rate for a maximum DRI value of 15.4 is less than $0.5 \%$ percent (see Figure 25). Based on cadaver data, the spinal injury rate for a maximum DRI of 15.4 is less than $1 \%$. Likewise, only one low-risk Brinkley Index curve exceeded a magnitude of 1.0. This curve was for the chest of ATD-1 for the 12.69-ft/s vertical drop test. The medium-risk curve for the chest of this occupant did not exceed 1.0. Therefore, the maximum possible risk of injury would be considered between lowto-medium. All other Brinkley Index curves were well below a magnitude of 1.0. It is important to remember that the skid gear collapsed during the $12.69-\mathrm{ft} / \mathrm{s}$ drop test, resulting in impact of the steel plate and seating platform with the concrete surface.

\section{ANALYTICAL MODELING}

A finite element model of the final skid gear test article including dummy occupants was developed using the commercial non-linear, explicit transient dynamic code, LS-DYNA [14]. The model was developed to evaluate the human occupant modeling capabilities in LS-DYNA by simulating a relatively simple test configuration, namely the HeloWerks skid gear reported herein. The test data generated from the 8.35 - $\mathrm{ft} / \mathrm{s}$ vertical drop test pristine configuration of the final skid gear design was used to validate the analytical results.

The complete LS-DYNA finite element model of the modified skid gear is shown in Figure 38. The structural model consists of: 52 parts; 11,902 nodes; and 11,735 elements including 8,842 Belytschko-Tsay quadrilateral shell elements, 1,565 hexagonal solid elements, 925 beam elements, 371 seatbelt elements, and 32 lumped mass elements. Material properties were defined for the various parts including *MAT_PLASTIC_KINEMATIC for the aluminum representing the skid gear saddles and *MAT_ELASTIC for the remainder of the skid gear and steel plate. 
The seat foam fillers were represented using solid elements that were assigned a material model in LS-DYNA called *MAT_CRUSHABLE_FOAM. Material characterization testing was performed to evaluate the behavior of the two seat foams, Styrofoam and polyisocyanurate. The test data were used as input for the material model. The seat foam material characterization test results are presented in Figure 39.

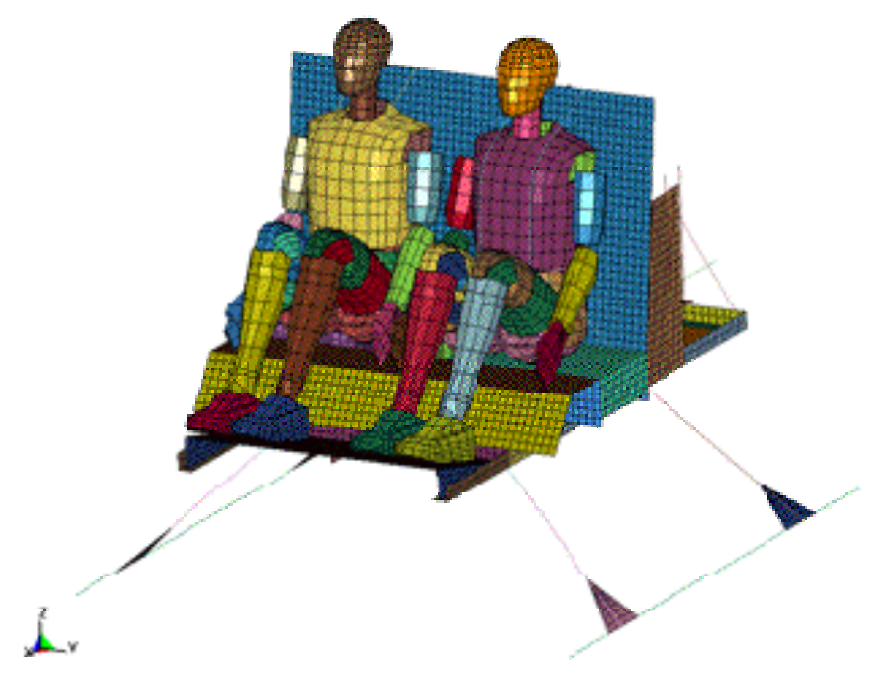

Figure 38. LS-DYNA model of the skid gear with occupants.

The skid gear was modeled using circular cross-section beam elements of varying thickness. Concentrated masses were used in the model to represent the ballast weights. Two Hybrid III $95^{\text {th }}$ percentile male occupants were inserted into the structural model using the *COMPONENT_HYBRIDIII command. These models represent the human body using rigid links, surrounded by ellipsoids, with kinematic joints that mimic the motion of the human body. Once added, the two occupants were positioned using LS-PrePost [15], which is the pre- and post-processing sodtware for LS-DYNA. Seatbelt elements were used to constrain the motion of the occupant models. Also, contact surfaces were defined to represent contact between the skid gear and the impact surface, between the occupants and the seatbelts, and between the occupants and the seating platform. The model was executed in LS-DYNA version 971 on a Linux workstation computer with a single processor. A simulation time of 0.2 seconds required 7 hours and 45 minutes of CPU time.

Comparisons of the filtered vertical acceleration responses of the pelvis and chest of the left and right ATD dummy occupants with LS-DYNA analytical predictions are shown in Figures 40 and 41, respectively. Both the experimental and analytical results were filtered with a SAEJ211 equivalent filter with a cut-off frequency of $60 \mathrm{~Hz}$. As a reminder, ATD-1 is seated on the Styrofoam stack on the left side of the test article and ATD-2 is seated on the polyisocyanurate foam blocks on the right side of the test article. The analytical results accurately predict the peak acceleration values, as well as the general acceleration trends. However, the ATD chest responses display a slightly slower onset rate of acceleration as compared to the test data. 
Stress, psi

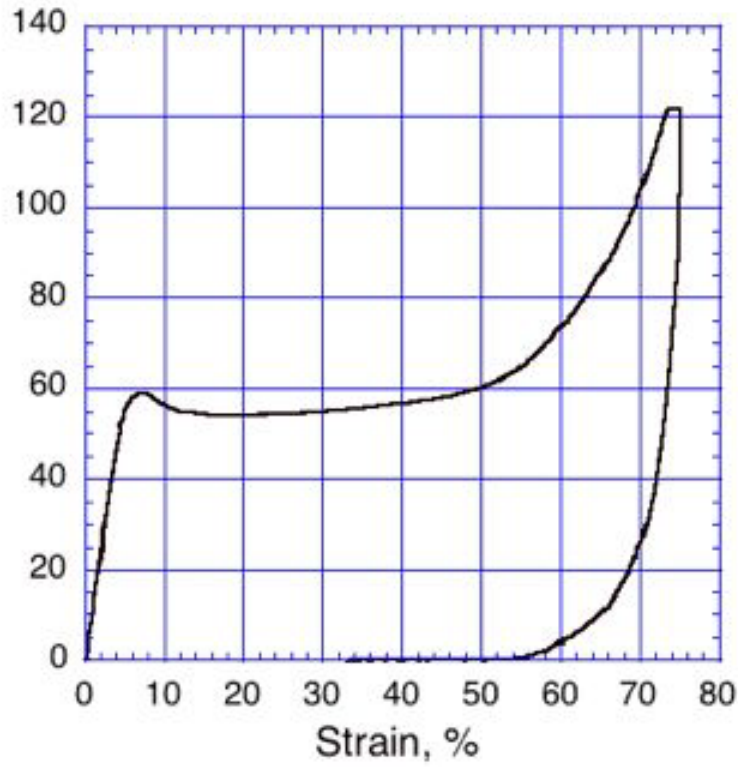

(a) Polyisocyanurate.
Stress, psi

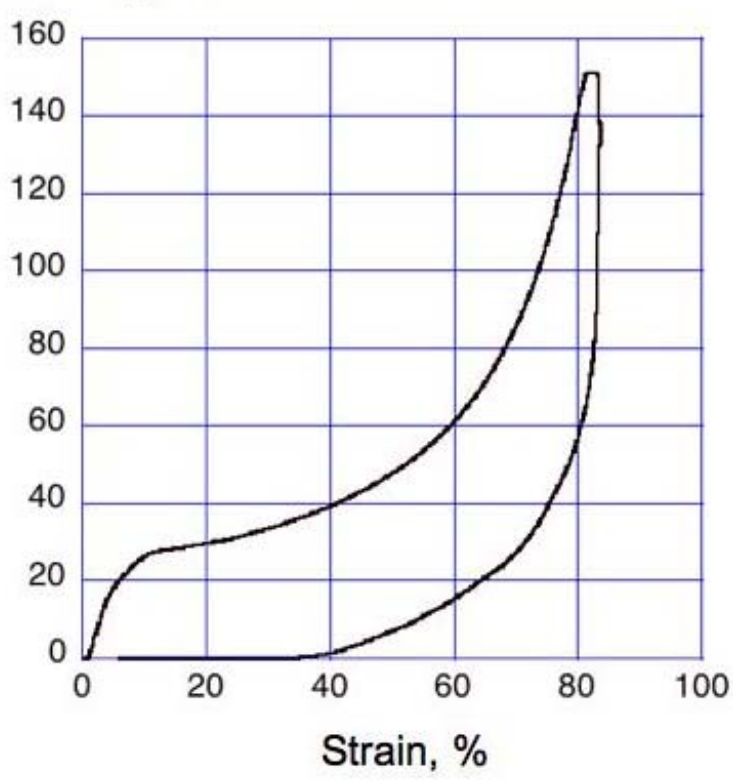

(b) Styrofoam.

Figure 39. Seat foam material characterization test results.

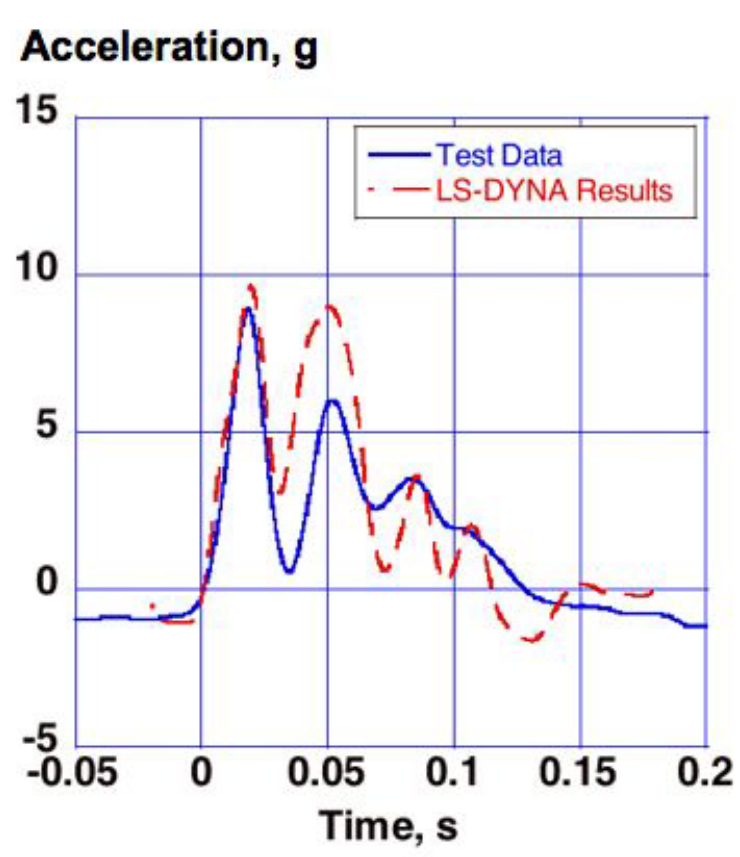

(a) Pelvis response.

\section{Acceleration, $\mathbf{g}$}

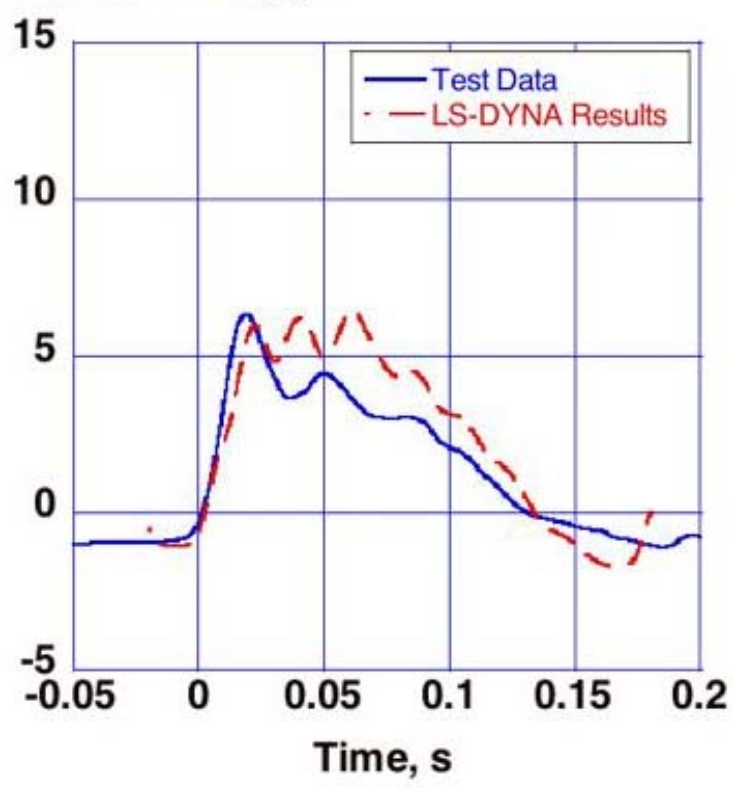

(b) Chest response.

Figure 40. ATD-1 test data versus updated LS-DYNA results for the $8.35-\mathrm{ft} / \mathrm{s}$. 


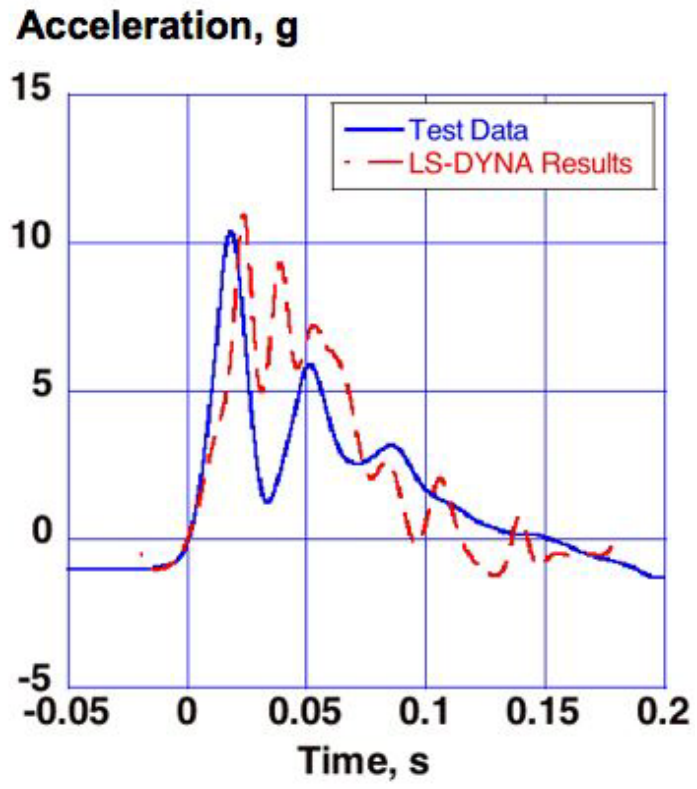

(a) Pelvis response.

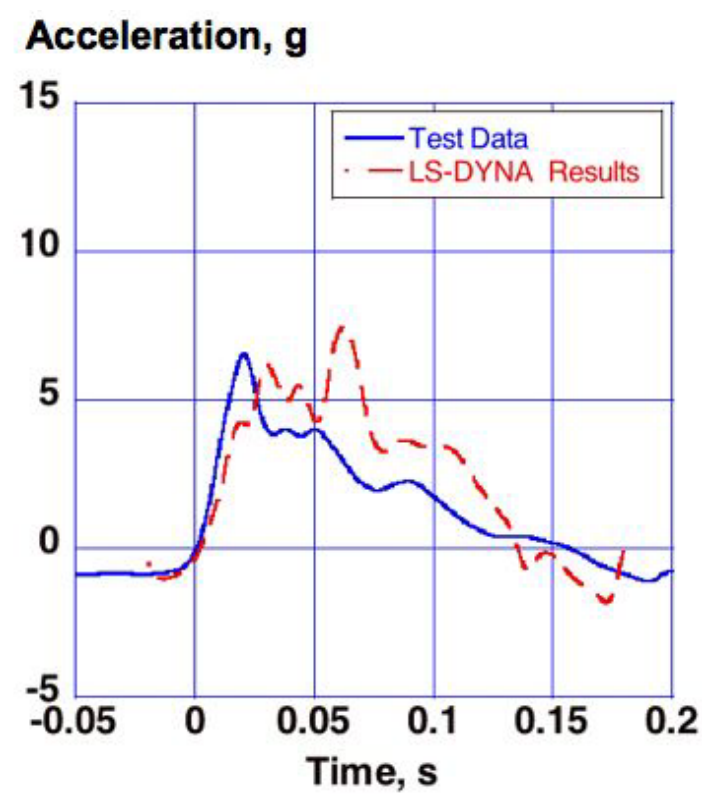

(b) Chest response.

Figure 41. ATD-2 test data versus updated LS-DYNA results for the $8.35-\mathrm{ft} / \mathrm{s}$.

\section{DISCUSSION OF RESULTS}

Two vertical drop tests were performed on a test article incorporating the initial skid gear redesign, one at $5-\mathrm{ft} / \mathrm{s}$ and the second at $8-\mathrm{ft} / \mathrm{s}$. The skid gear was damaged during the first test, though the amount of damage was considered minor and the second test was performed. No attempt was made to repair the damage following the initial test. During the 8 - $\mathrm{ft} / \mathrm{s}$ drop, the gear collapsed. It is speculated that the damage to the gear from the initial drop test contributed significantly to the failure of the gear in the second, more severe, drop test. Ideally, these tests should have been performed on two separate test articles, both in pristine condition, to fully understand skid gear response as a function of increasing impact velocities. However, project resources did not allow for this approach. It is interesting to note that only minor damage occurred to the final skid gear design that was tested at $8.35-\mathrm{ft} / \mathrm{s}$ in the second series of tests.

The occupant data collected from the two $95^{\text {th }}$ percentile Hybrid III male ATDs proved useful in performing an injury assessment. The DRI and Brinkley human injury prediction models were applied using the test data from the series of drop tests performed in December 2006. The results of the injury assessment indicate a maximum DRI value of 15.4, which is associated with a spinal injury risk of less than $0.5 \%$, based on operational data during ejection seat incidents. The DRI assessment is based solely on the vertical acceleration responses of the ATDs. However, the Brinkley Index includes acceleration responses in three orthogonal directions. Since tri-axial accelerometers were placed in the chest and pelvis of the ATD occupants, this human injury criertion was applied. The Brinkley model indicated that only the chest acceleration response of ATD-1 for the $12.69 \mathrm{ft} / \mathrm{s}$ vertical drop test was greater than 1.0, indicating an injury risk level between low to medium. All other Brinkley Indices were well below 1.0. Note that the skid gear collapsed during the $12.69-\mathrm{ft} / \mathrm{s}$ vertical drop test resulting in significantly higher occupant accelerations due to impact of the seating platform with the concrete surface. 
In both test articles, foam filler was used in the seat platform. However, no discernable crushing of the Styrofoam or the polyisocyanurate foam was measured during any of the vertical drop tests. The crush response of each material is shown in Figure 39. Polyisocyanurate foam exhibits a average crush stress of approximately $57 \mathrm{psi}$. One recommendation for improving the crashworthiness performance of the system would be to incorporate a lower crush stress foam material. Crushing of the foam would provide a secondary means of energy absorption.

The LS-DYNA models representing the $95^{\text {th }}$ percentile male Hybrid III dummy occupants performed well during the simulations and generally good agreement, in that the peak magnitudes and durations correlated within $20 \%$, was obtained with test data. The peak accelerations in the chest and pelvis were well predicted; however, some differences were seen in the acceleration onset rate. It should be noted that these dummy models were generally developed and validated for use in automotive crash simulations in which impulsive loading is primarily in the frontal plane. Rarely would an occupant experience vertical impulsive loading in an automotive crash, thus these models are not well validated for this condition.

Based on the test results and occupant injury assessment, the final skid gear design meets the requirements for landing loads for this category of helicopter, per FAR 27 [2].

\section{CONCLUSIONS}

Five vertical drop tests were performed on two different skid gear designs that were provided by HeloWerks, Inc. These skid gear were intended as a replacement for an existing composite design that did not perform well during an actual crash event of the Wasp prototype helicopter. The design goal for the gear was to meet the landing loads requirements specified in FAR Part 27 for helicopters weighing less than 7,000 lbs. An experimental program was conducted to evaluate the impact performance of the skid gear designs. The test article consisted of a skid gear mounted beneath a steel plate. A seating platform was attached to the upper surface of the steel plate, and two $95^{\text {th }}$ percentile Hybrid III male Anthropomorphic Test Devices (ATDs) were seated on the platform and secured using a four-point restraint system. The test article also included ballast weights to ensure the correct position of the Center-of-Gravity (CG). Test data were collected from accelerometers located on the steel plate, the seating platform, and the ATD dummy occupants.

Conclusions from this research project are listed below:

- The initial skid gear redesign was modified following the first two impact tests that were conducted at 5- and 8-ft/s. The gear collapsed following the 8 -ft/s vertical drop test. Modifications to the gear included increasing the outer diameter and wall thickness of the struts and shortening the length of the struts.

- The final skid gear design survived the 8.35 - and $10-\mathrm{ft} / \mathrm{s}$ vertical drop tests. The gear collapsed during a subsequent $12.69-\mathrm{ft} / \mathrm{s}$ drop test.

- An occupant injury assessment was performed for the three vertical drop tests that were conducted on the final skid gear design, using the Dynamic Response Index (DRI) and Brinkley Index. The risk of human injury, based on these models, is low.

- Based on the test results and the occupant injury assessment, the final skid gear design offers improved crash protection and achieves design goals for landing loads as for this category of helicopter. 
- A finite element model of the skid gear test article was developed using LS-DYNA including models of the two $95^{\text {th }}$ percentile Hybrid III male anthropomorphic test devices (ATDs). This model successfully predicted the ATD responses obtained during the 8.35$\mathrm{ft} / \mathrm{s}$ vertical drop test of the final skid gear design.

\section{REFERENCES}

1. Annex 1 Space Act Agreement (SAA) for Crash Safety Evaluation Between NASA Langley Research Center and HeloWerks, Inc., SAA1-807, October 24, 2006.

2. Code of Federal Regulations, Federal Aviation Regulations for Aviation Maintenance Technicians FAR AMT, Part 27 Airworthiness Standard: Normal Category Rotorcraft, 27.723 Landing Gear Shock Absorption Tests.

3. Tho, Cheng-Ho, Sparks, Chad E., Sareen, Ashish K., Smith, Michael R., and Johnson, Courtney, "Efficient Helicopter Skid Landing Gear Dynamic Drop Simulation," Proceedings of the American Helicopter Society $59^{\text {th }}$ Annual Forum, Phoenix, AZ, May 6-8, 2003.

4. Society of Automotive Engineers (SAE), Recommended Practice: Instrumentation for Impact Test - Part 1, Electronic Instrumentation, SAE J211/1, March 1995.

5. Stech, E. L. and Payne, P. R., "Dynamic Models of the Human Body," AAMRL-TR-66-157, Aerospace Medical Research Laboratory, Wright-Patterson Air Force Base, Ohio, 1969.

6. Brinkley, J. W. and Shaffer, J. T., "Dynamic Simulation Techniques for the Design of Escape Systems: Current Applications and Future Air Force Requirements," Aerospace Medical Research Laboratory; AMRL Technical Report 71-292, Wright-Patterson Air Force Base, Ohio, December 1971, AD 740439.

7. Coltman, J. W., Van Ingen, C., Johnson, N. B., and Zimmerman, R. E., "Crash Survival Design Guide, Volume II - Aircraft Design Crash Impact Conditions and Human Tolerance," USAAVSCOM TR 89-D-22B, December 1989.

8. Brinkley, J. W. and Mosher, S. E., "Development of Acceleration Exposure Limits to Advanced Escape Systems," Implications of Advanced Technologies for Air and Spacecraft Escape, AGARD-CP-472, April 24-28, 1989.

9. Mosher, S. E., "DYNRESP Six Degree-of-Freedom Model for Injury-Risk Evaluation User's Manual," NASA Johnson Space Center, April 29, 1993.

10. Anon., "Human Tolerance to Impact Conditions As Related to Motor Vehicle Design SAEJ885," APR 80, SAEJ885, Society of Automotive Engineers, Inc., Warrendale, PA, April 1980.

11. Gadd, C. W., "Use of a Weighted-Impulse Criterion for Estimating Injury Hazard, " Proceedings of the Tenth Stapp Car Crash Conference, Society of Automotive Engineers, New York, 1966. 
12. Eiband, A. M., "Human Tolerance to Rapidly Applied Accelerations: A Summary of the Literature," NASA Memorandum 5-19-59E, National Aeronautics and Space Administration, Washington D.C., June 1959.

13. Desjardins, S. P., Zimmerman, R. E., Bolukbasi, A. O., and Merritt, N. A., "Crash Survival Design Guide, Volume IV-Aircraft Seats, Restraints, Litters, and Cockpit/Cabin Delethalization," USAAVSCOM TR 89-D-22B, December 1989.

14. Anon, “LS-DYNA Keyword User's Manual,” Version 971, Livermore Software Technology Company, Livermore, CA, August 2006.

15. Anon., "LS-PRE/POST Version 1.0 Manual," Livermore Software Technology Company, Livermore, CA, August 27, 2002. 


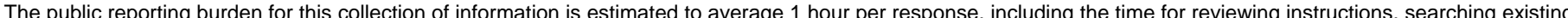

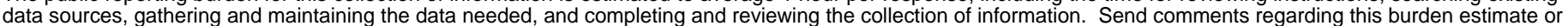

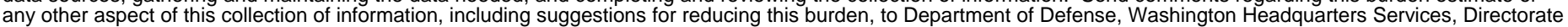
for Information Operations and Reports (0704-0188), 1215 Jefferson Davis Highway, Suite 1204, Arlington, VA 22202-4302. Respondents should be aware that

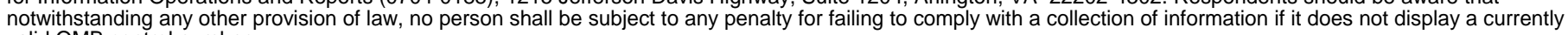
valid OMB control number.

PLEASE DO NOT RETURN YOUR FORM TO THE ABOVE ADDRESS.
1. REPORT DATE (DD-MM-YYYY)
2. REPORT TYPE
3. DATES COVERED (From - To)
01-09-2007
Technical Memorandum
Oct 2006 - May 2007

4. TITLE AND SUBTITLE

Vertical Drop Testing and Analysis of the Wasp Helicopter Skid Gear

5a. CONTRACT NUMBER

5b. GRANT NUMBER

5c. PROGRAM ELEMENT NUMBER

\section{AUTHOR(S)}

Jackson, Karen E.; and Fuchs, Yvonne T.

5d. PROJECT NUMBER

SAA1-807

5e. TASK NUMBER

5f. WORK UNIT NUMBER

877868.02.07.07.05.02

\section{PERFORMING ORGANIZATION NAME(S) AND ADDRESS(ES)}

8. PERFORMING ORGANIZATION

NASA Langley Research Center REPORT NUMBER

Hampton, Virginia 23681-2199

9. SPONSORING/MONITORING AGENCY NAME(S) AND ADDRESS(ES)

National Aeronautics and Space Administration

Washington, DC 20546-0001
10. SPONSORING/MONITOR'S ACRONYM(S)

NASA

11. SPONSORING/MONITORING REPORT NUMBER

NASA/TM-2007-214901

\section{DISTRIBUTIONIAVAILABILITY STATEMENT}

Unclassified - Unlimited

Subject Category: 39

Availability: NASA CASI (301) 621-0390

\section{SUPPLEMENTARY NOTES}

\section{ABSTRACT}

This report describes an experimental program to assess the impact performance of a skid gear for use on the Wasp kit-built helicopter, which is marketed by HeloWerks, Inc. of Hampton, Virginia. In total, five vertical drop tests were performed. The test article consisted of a skid gear mounted beneath a steel plate. A seating platform was attached to the upper surface of the steel plate, and two 95th percentile Hybrid III male Anthropomorphic Test Devices (ATDs) were seated on the platform and secured using a four-point restraint system. The test article also included ballast weights to ensure the correct position of the Center-of-Gravity (CG). Twenty-six channels of acceleration data were collected per test at 50,000 samples per second. The five drop tests were conducted on two different gear configurations. The details of these test programs are presented, as well as an occupant injury assessment. Finally, a finite element model of the skid gear test article was developed for execution in LS-DYNA, an explicit nonlinear transient dynamic code, for predicting the skid gear and occupant dynamic responses due to impact.

\section{SUBJECT TERMS}

skid gear impact performance, dynamic finite element analysis, human occupant simulation, crashworthiness, impact testing, LS-DYNA analysis, dynamic structural analysis

16. SECURITY CLASSIFICATION OF:

\begin{tabular}{c|c|c|}
\hline a. REPORT & b. ABSTRACT & c. THIS PAGE \\
$\mathrm{U}$ & $\mathrm{U}$ & $\mathrm{U}$ \\
\hline
\end{tabular}

\section{LIMITATION OF ABSTRACT}

UU
18. NUMBER OF PAGES
35

\section{9a. NAME OF RESPONSIBLE PERSON}

STI Help Desk at email: help@sti.nasa.gov 19b. TELEPHONE NUMBER (Include area code) 